\title{
Floppy-Disk System for Punched-Tape Reader Emulation
}

\section{J. E. Hopwood}

Prepared by

Sandia Mational Laboratories

Albuquerque, New Mexico 87185 and Livermore, California 94550

for the United States Department of Energy

under Contract DE-AC04-76DP00789

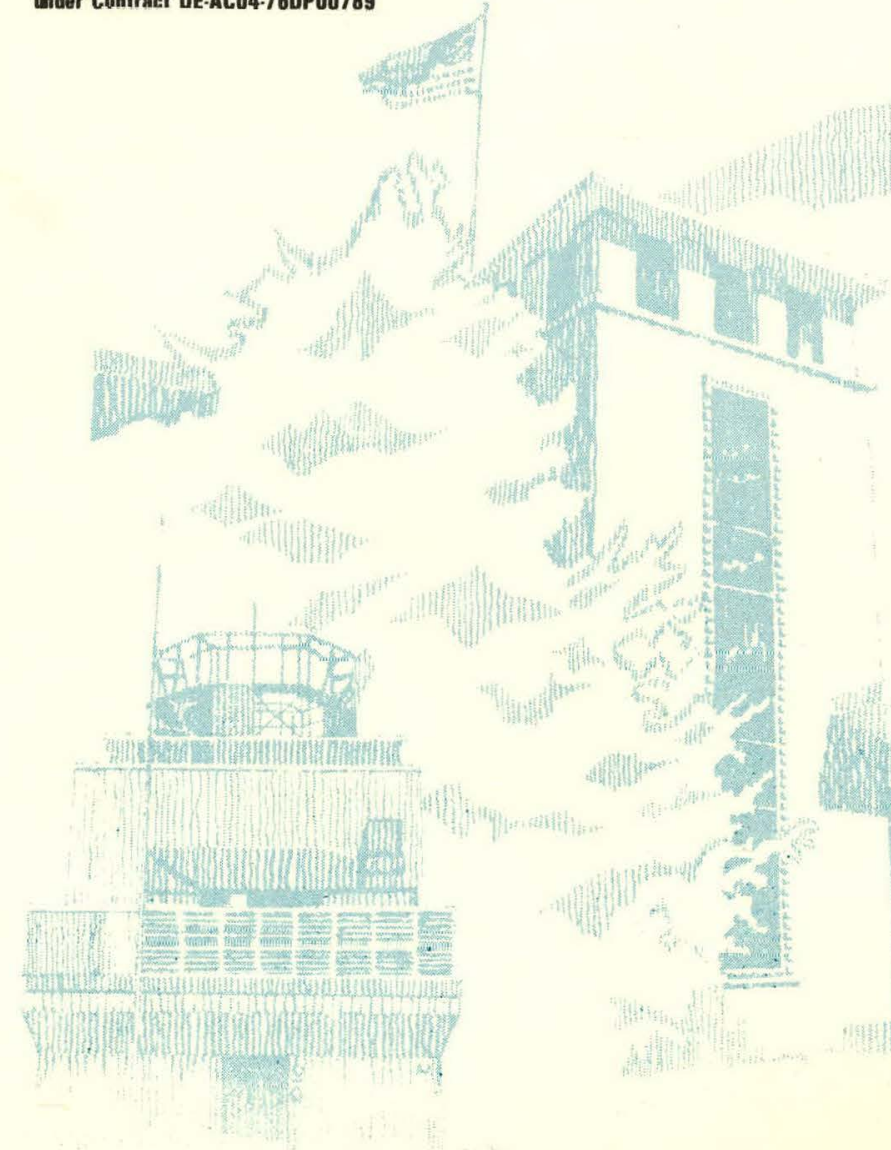




\section{DISCLAIMER}

This report was prepared as an account of work sponsored by an agency of the United States Government. Neither the United States Government nor any agency Thereof, nor any of their employees, makes any warranty, express or implied, or assumes any legal liability or responsibility for the accuracy, completeness, or usefulness of any information, apparatus, product, or process disclosed, or represents that its use would not infringe privately owned rights. Reference herein to any specific commercial product, process, or service by trade name, trademark, manufacturer, or otherwise does not necessarily constitute or imply its endorsement, recommendation, or favoring by the United States Government or any agency thereof. The views and opinions of authors expressed herein do not necessarily state or reflect those of the United States Government or any agency thereof. 


\section{DISCLAIMER}

Portions of this document may be illegible in electronic image products. Images are produced from the best available original document. 
Issued by Sandia National Laboratories, operated for the United States

Department of Energy by Sandia Corporation. NOTICE. Tliss Iepurt Was prepared as an account of work sponsored by
an agency of the United States Government. Neither the United States Government nor any agency thereof, nor any of their employees, nor any of the contractors, subcontractors, or their employees, makes any warranty, express or implied, or assumes any legal liability or responsibility for the accuracy, completeness, or usefulness of any information, apparatus, product, or process disclosed, or represents that its use would not infringe privately owned rights. Reference herein th any woulic commercial product process or eerice by trade namy specific commercial product, process, or service by trade name, trademark, manufacturer, or otherwise, does not necessarily constitute or imply its endorsement, recommendation, or favoring by the United States Government, any agency thereof or any of their contractors or subcontractors. The views and opinions expressed herein do not necessarily state or reflect those of the United States Government, any agency thereof or any of their contractors or subcontractors.

Printed in the United States of America Available from

National Technical information Service 5285 Port Royal Road Springfield, VA 22161

NTIS price codes

Printed copy: A04

Microfiche copy: A01 


\section{PAGES 1 to 2 WERE INTENTIONALLY LEFT BLANK}


SAND82-8016

UC-13

Unlimited Release

Printed August 1982

\title{
FLOPPY-DISK SYSTEM FOR PUNCHED-TAPE \\ READER EMULATION
}

\author{
J. E. Hopwood \\ Electronic Technology Division \\ Sandia National Laboratories, Li vermore
}

\section{ABSTRACT}

This report describes the application of minifloppy disk systems to numerically-controlled machine tools at Sandia, Livermore, as an alternative to time-consuming and unreliable punched-tape readers. 


\section{CONTENTS}

Page

Introduction

9

Minifloppy Disk System 9

$\begin{array}{ll}\text { Data Flow } & 10\end{array}$

$\begin{array}{ll}\text { Advantages of Floppy Disks } & 13\end{array}$

Information on the Disk Drive and Emulator 16

APPENDIX A--NC MACHINE TOOLS CONVERTED TO MINIFLOPPY 23 DISK SYSTEM

APPENDIX B--WIRING DIAGRAM OF DATA INPUT CIRCUITRY FOR EACH NC MACHINE TOOL 


\section{ILLUSTRATIONS}

No. $\quad$ Page

1 Fl ow of Part Description Data to Disk System 11

2 Minifloppy Disk System 12

3 Minifloppy Disk System with Computer Interface 14

4 Minifloppy Disk Drive 17

5 Minifloppy Disk System Specifications 19

6 Minifloppy. Disk System File Management Commands 20

7 Read-only Punched Emulator Specifications 21

8 Emulator File Management Commands 22 


\section{ACKNOWLEDGEMENT}

The author wishes to express his appreciation to Bruce Affeldt (8414-2), NC programmer: Without his cooperation this project could not have been completed. 


\title{
FLOPPY DISK SYSTEM FOR PUNCHED TAPE READER EMULATON
}

\section{Introduction}

\begin{abstract}
For several years Sandia National Laboratories, Livermore (SNLL), has been seeking alternatives to punched-tape readers on numerically-controlled (NC) machine tools. SNLL possesses every generation of NC equipment, from a 1960 vintage GE 100 S control using a Tally mechanical tape reader to a Kearny and Trecker Model $180 \mathrm{CNC}$ with a 300-cps photoelectric reader. The. readers are the primary source for malfunctions. A system had been developed previously that read part description data from a cartridge to an Ampex Core Memory. The NC equipment then read the memory in a similar manner to reading punched tape. The new system performed well but had a small program capacity. Other commercial storage systems were rejected on the basis of cost-effectiveness and lack of versatility.

Recent advances in mass data storage devices has made possible a lowcost minifloppy disk system with a self-contained 5.25-inch floppy disk drive, power supply, microprocessor-based controller, and RS232C interface. This system was manufactured by GUC Products in San Diego, California.
\end{abstract}

\section{Minifloppy Disk System}

SNLL worked with GUC to develop the interface electronics to the numerical controls. The interface, incorporated on a single printed wiring board (PWB), is adaptable to any model of NC equipment by simply setting miniature switches on the board. After debugging the system, it was successfully demonstrated on three NC machines, a Gerber photoplotter, and a Gerber coordinate digitizer.

Before equipping the SNLL NC machine tools with a minifloppy disk drive, it was first necessary to obtain disk writing capability. This was accomplished several months prior to installation. Once installed, the minifloppy disk system was used to store part description data that had been sent from a CDC 6600 computer through a modem to a tape punching machine.

Using the tape puncher was a slow process (600 bits per second (bps)), requiring 45 minutes to complete a 600-foot tape. 0ccasionally, the computer failed during this operation, and it had to be repeated. The mini-- 
floppy disk system can send data at 9600 baud, a three-minute task. After storage, the disk system is taken of $f-l$ ine and the baud rate changed to 600 bps and read to the tape puncher. This gives the disk system a dual purpose: recording data on a disk for direct use on NC equipment, or being used for off-line tape-punching.

Data Flow

The following briefly describes the flow of the part description data being written to the minifloppy disk system. Refer to Figure 1.

After the programmers text file has been processed by the CDC 6600 APT program, and the appropriate post-processor invoked, the part description data is stored in a batch file within the computer. By commands entered through the terminal, the permanent file is transmitted at a baud rate of 9600 bps across signal lines in an asynchronous, serial-EIA fornat to the modem (the voltage levels conform to RS232C specifications). Immediately prior to valid data transmission, a ASCII control character $(D C-2)$ is inserted by the computer program. The minifloppy disk systems, which is constantly testing the data string, senses the $\mathrm{DC}-2$ and begins to store every transmitted character until sensing a DC-4 character, which is transmitted at the conclusion of the permanent file. At this point, the disk is delivered to the NC machine tool.

If the machine had not yet been equipped with a minifloppy disk drive, a punched tape was generated. To do this, the minifloppy baud rate is changed, via the front panel keypad, from 9600 to 600 bps. After selecting the disk file number to be punched, the entire file is transmitted to the tape punch machine. The punched tape is then delivered to the NC machine tool. Figure 2 shows the read-write minifloppy disk drive. HP 2640

terminal, Teklrunix 4631 hard-copy machine, and DSI tape puncher. This equipment is located in the programmer's office.

The minifloppy disk drive at the NC machine is a read-only tape reader emulator. The outputs are: eight-bit parallel data synchronous to the Tape Forward Command (TFC) issued by the NC machine, and Sprocket Clock that the NC machine tool uses to sense that a valid character is present. By mearis of miniature slide switches internal to the disk drive, the signal level, logic state, and transfer rate are selectable for each NC machine model. The capacity of the minifloppy disk is 179,000 bytes, equivalent to 1488 feet of punched tape. The punched tape reader is still used in a back-up role. To reinsert the tape reader into the data input circuitry, an adapter connector is installed in place of the emulator.

Another application of the minifloppy system outside of the NC machinc tool area involved a Gerber Model GCD-1 Coordinate Digitizer. An interface was developed to properly format the digitized data, convert to RS232C voltage levels, and transmit it to a file in the CDC 6600 computer. Because the computer frequently breaks down during the long digitizing process, data which was assumed to be going into file would be lost. To prevent this condition, the minifloppy disk drive is placed in parallel with the modem, as 


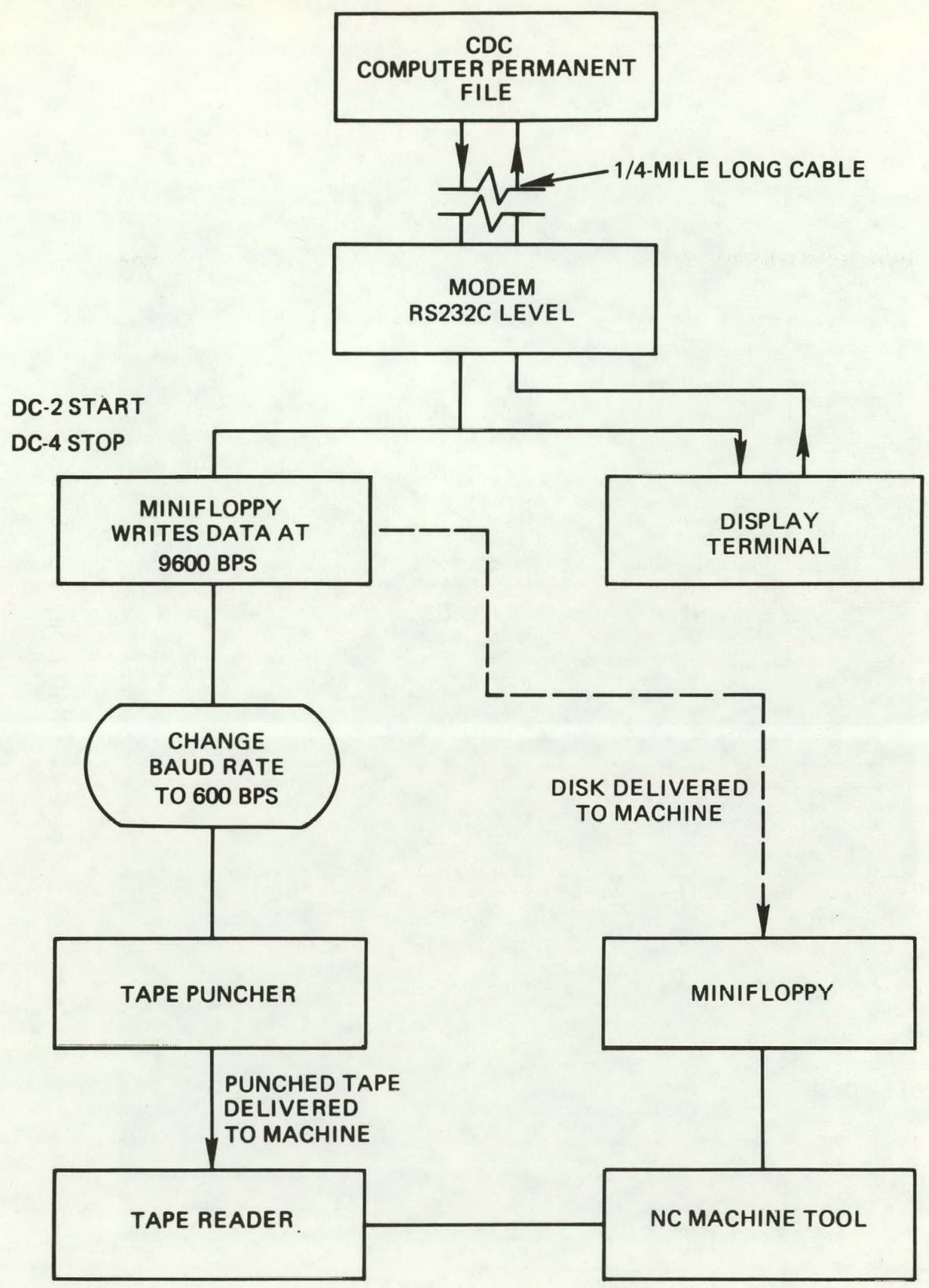

Figure 1. Flow of Part Description Data to Disk System 


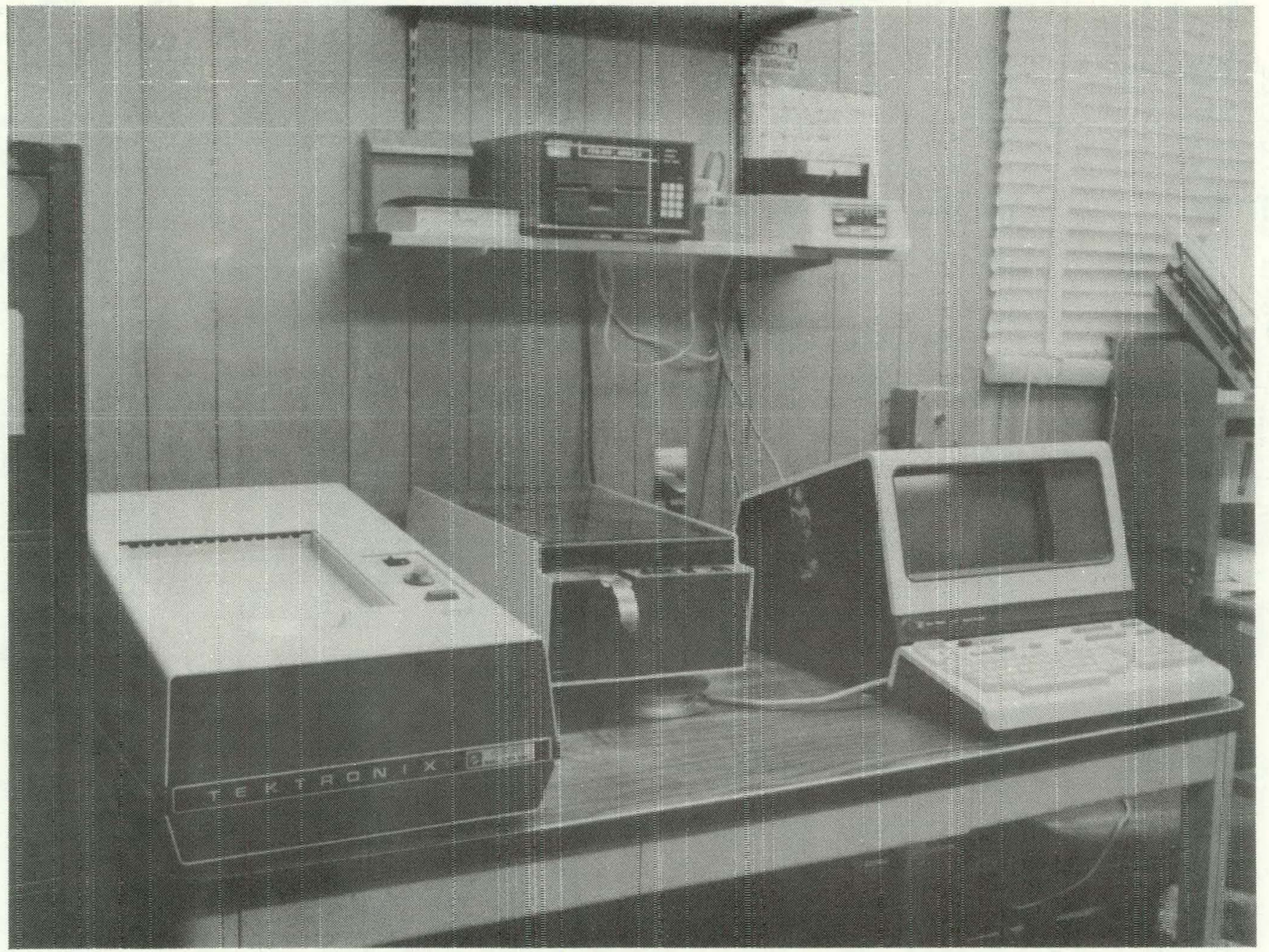

Figure 2. Minifloppy Disk System 
shown in Figure 3. Now, if a failure occurs without the operator's knowledge, the data is saved on the disk and can later be transmitted to the computer.

\section{Advantages of Floppy Disks}

1. Elimination of paper-tape punching.

A 600-foot tape takes about 45 minutes to punch. The same data written to disk takes approximately three minutes. Historically, the punch mechanism has been troublesome.

2. Cost Saving.

Mylar tape currently costs $\$ 50.00$ per 1,000 -foot roll. Floppy disks cost approximately $\$ 5.00$ each and are reusable for an indefinite length of time. Each disk will hold 1,488 feet of punched tape data. At four rolls per week, the savings amount to $\$ 200$ per week, or $\$ 10,400$ per year. The cost of the minifloppy disk system is approximately $\$ 2,000$.

3. Greater data transfer speed.

The speed of data transfer from the CDC 6600 is 9600 bps versus 600 bps when tape-punching is required.

4. Greater reliability.

With the faster transfer rate, there is less chance of the computer failing in the middle of data transfer.

5. More efficient use of data terminals.

When punching tape, the data terminal is on-line making it unavailable for normal programming use. The fast recording time increases use time.

6. Storage space reduced.

The amount of storage space is reduced by no longer having to save puriched tape.

7. Tape handling is completely eliminated.

With the disk system, the operator inserts the disk and then simply selccts the file to be read. Inslalling and threading punched tape is more complex. 


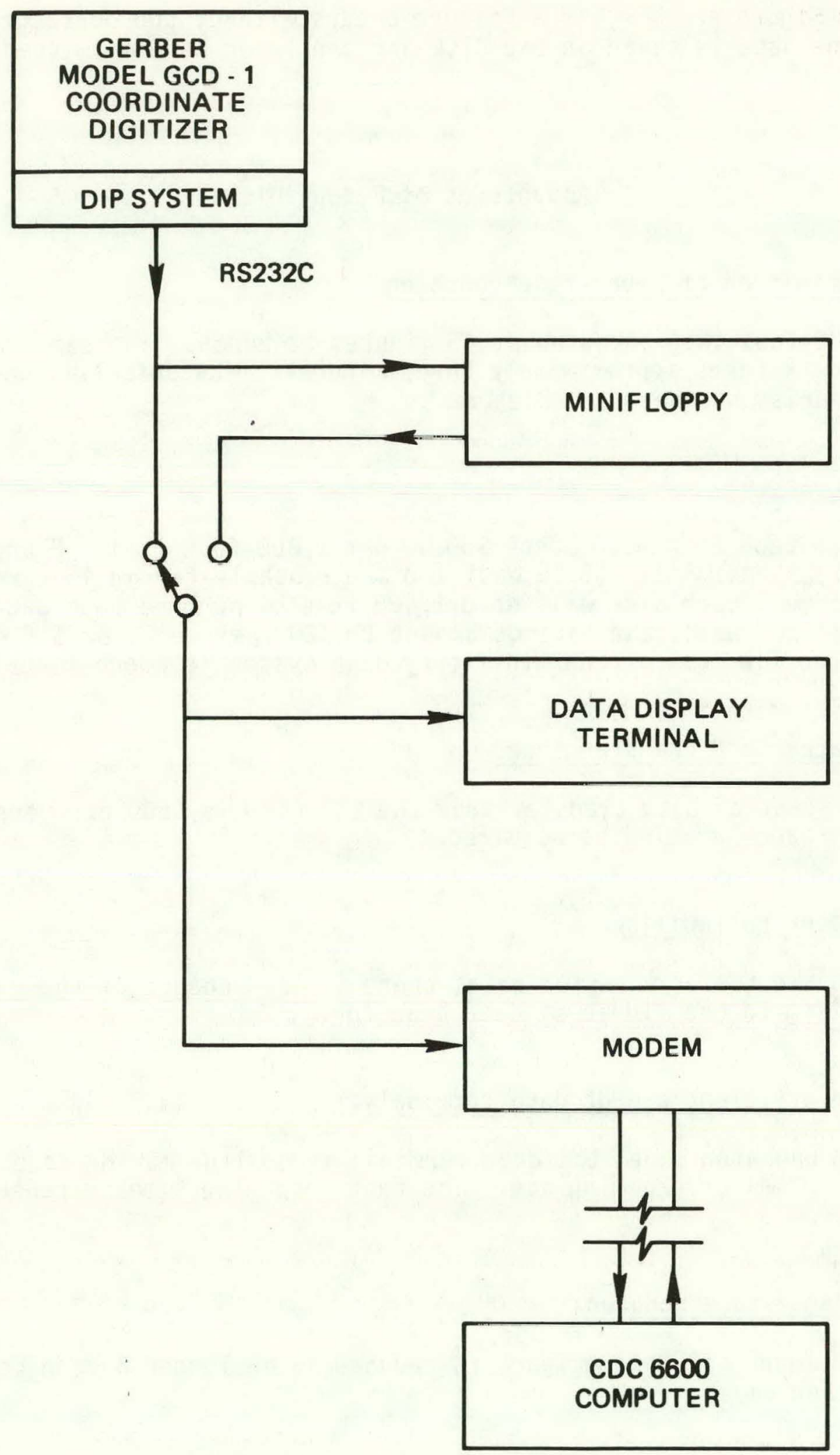

Figure 3. Minifloppy Disk System with Computer Interface 


\section{Greater program storage capability.}

Punched tape reels will hold only 600 feet of tape. The disk will contain program storage equivalent to 1,488 feet of tape.

9. Multiple-program storage on a single disk.

Each disk contains 26 programs. The operator selects the desired program via keyboard.

10. Lower initial cost than tape reader.

The price difference between a tape reader and a minifloppy disk system is approximately $\$ 1,000$.

11. Less maintenance.

The minifloppy disk drive requires only periodic cleaning of the disk heads.

12. Impact of floppy disks.

The GUC floppy disk drive system has had a large impact on the programmer:

a. The amount of time necessary to get changes ont o the shop floor has been reduced dramatically. The main reason is that a tape punching machine takes almost an hour, while the same data on floppy disk only requires minutes (two or three minutes at most).

b. On machines without sequence search facilities, each tool change or other convenient breaking-point can be set up as a separate file on the floppy disk. This has several advantages:

(1) It allows the machine tool operator to run a section of the data over without having to start the data at the beginning and running through to the area to be remachined (useful for tool wear or breakage).

(2) It allows the machine tool to be shut down and restarted without having to run the entire job again.

(3) On the DAC printed circuit drill and router, when using paper tape, it was necessary to punch individual tapes for each hole size. When routing the board, the tapes had to be broken into 300-foot lengths. Since the machine does not have circular or linear interpolation, this tape length is reached very quickly because all nonaxis movements must be broken down to 0.001 of an inch. With the advent of the floppy disk, the entire job is stored on one disk and separated into various files: 
File \#1 - S and T hole.

File \#2 - First hole size.

File \#3 - Next hole size.

File \#N - File contains router information.

c. On CNC machines, minor corrections can now be made in the main program without the operator having to edit data, thereby keeping the APT program current at all times.

d. Reliability of data transfer is much better (no punch hangs or mispunches in tape).

e. Floppy disks are an easier and more compact data storage medium.

f. Operators have accepted the minifloppy disk system and have expressed the following comments:

(1) No tape handling.

(2) No threading of machine.

(3) Easier storage.

(4) More data on floppy disks than possible on tape.

(5) No waiting for rewinding.

(6) Easier search facility.

y. There are nu significant changes in the programmer's routine. The floppy disk setup routine is similar to paper tape.

Information on the Disk Drive and Emulator

Figure 4 shows the minifloppy disk drive. A latching access door provides for the disk inserting and removal. The purpose of the indicators and controls are as follows:

Activity

St atus
- This indicator flashes when activity is detected on the transmit or receive interface lines.

- This indicator identifies the three-digit numeric display as an error code or status code. 


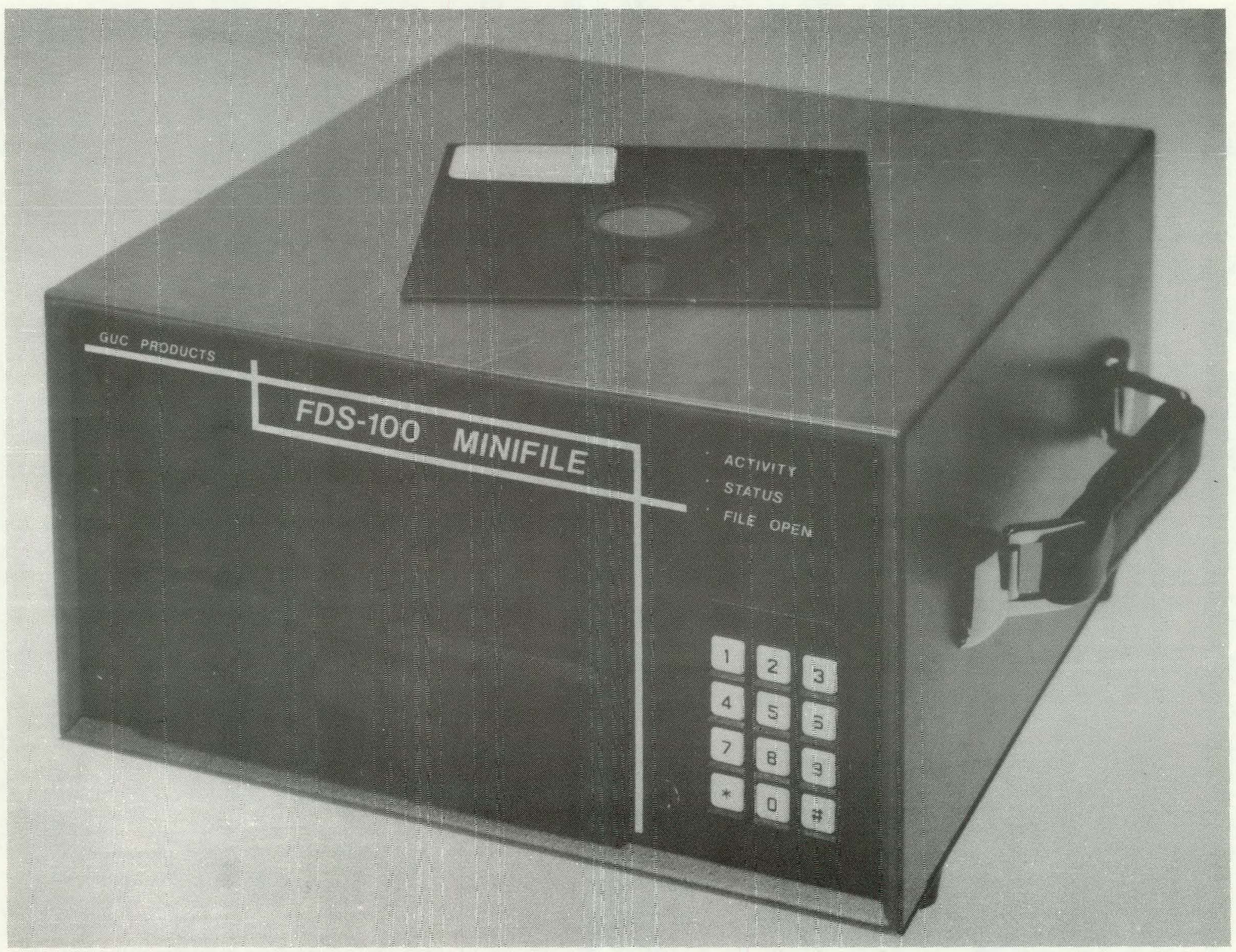


File Open

Numeric Display

Keyboard
- This indicator flashes when a file is selected for reading or writing.

- System status and error information is communicated to the operator by means of a three-digit, sevensegment numeric display. (The status codes and error messages will be explained later in this report). Through this display, the operator may obtain additional information on command such as the contents of the directory and free space available.

- The entire file management is in firmware. Control of all the file management functions is available to the operator by medns of a keyboard. The entry sequence for the functions will be explained later. Figure 5 lists the specifications for the read-write minifluppy disk system, and Figure 6 lists the file management commands. Figure 7 lists the specifications for the read-only punched emulator, and Figure 8 lists its file management commands. In order to aid the machine tool operator in selecting a file (part description program) the $2 \mathrm{key}$, and the * key and \# key are imprinted with the words RUN-FILE and ENTER, respectively. 
179,000 BYTES NET, DOUBLE SIDED

EQUIVALENT TO 1488 FEET OF PUNCHED TAPE
CAPACITY

MAXIMUM FILES

INTERFACE

BAUD RATES

PACKAGE

RECORDING FORMAT
26

SERIAL, ASYNCHRONOUS, RS232C LEVELS

8 BIT DATA

1 START BIT

2 STOP BITS

$50,75,110,135,150,300,600,1200$,

$1800,2000,2400,3600,4800,7200,9600$

PORTABLE WITH CARRYING HANDLE

$5-1 / 4^{\prime \prime}$ H X 10" WX 10-1/2" D

160 BYTES/SECTOR NET

16 SECTORS/TRACK

35 TRACKS/SURFACE

2 SURFACES

RECORDING MEDIUM 5-1/4" FLOPPY DISKETTE, 16 SECTOR

SUGART SA155 OR EQUIVALENT

HARD ERRORS

1 IN 100 BILLION BITS

SOFT ERRORS

HANDLED INTERNALLY AND LOGGED

COST
APPROXIMATELY $\$ 2,000$

Figure 5. Minifloppy Disk System Specifications 


$\begin{array}{ll}\text { 1*N\# } & \text { DEFINE FILE } \\ 2 * N \# & \text { SELECT FILE } \\ 3 \# & \text { CLOSE FILE } \\ 4 \# & \text { FREE BLOCKS } \\ 5 \# & \text { DIRECTORY }\end{array}$

13*N\# SET BAUD RATE

14"N\# SYNC MODE SELECT

73\# RESET

91\# FORMAT

92\# INITIALIZE DIRECTORY

96\# VERIFY DISKETTE

97\# COMPRESS DISKETTE

98*NH DELETE FILE

Figure 6. Minifloppy Disk System File Management Commands 
FUNCTION

CAPACITY

INTERFACE - INPUTS
OUTPUTS

$-$

SIGNAL LEVELS

LOGIC STATE

TRANSFER RATE

FORMAT

MEDIA

HARD ERRORS

SOFT ERRORS
READ ONLY PAPER TAPE READER EMULATION

178,560 BYTES NET OR 1488 FT. OF PAPER TAPE

TAPE FORWARD COMMAND (TFC) LEVEL OR EDGE TRIGGERED

8 BIT PARALLEL DATA SYNCHRONOUS TO TFC SPROCKET CLOCK

TAPE/READY

TAPE FORWARD ACKNOWLEDGE

INTERNALLY OR EXTERINALLY SOURCED OV/5V, OV/6V, OV/12V

SELECTABLE FOR EACH : INPUT AND OUTPUT

60 CPS TO 1000 CPS

160 BYTES/SECTOR NET

16 SECTORS/TRACK

35 TRACKS/SURFACE

2 SURFACES

5-1/4" FLOPPY DISKETTE, 16 SECTOR

SUGART SA155 OR EQUIVALENT

1 IN 100 BILLION BITS

HANDLED INTERNALLY AND LOGGED

Figure 7. Read-only Punched Emulator Specifications 


\section{2"N\# - SELECT FILE (RUN-FILE-N-ENTER) \\ 3\# CLOSE FILE \\ 4\# FREE BLOCKS \\ 5\# DIRECTORY \\ 12\# DISPLAY ERROR COUNT \\ 73H RESET \\ 96\# VERIFY DISKETTE}

Figure 8. Emulator File Management Commands 
APPENDIX A--NC MACHINE TOOLS CONVERTED TO MINIFLOPPY DISK SYSTEM

The following figures show NC machine tools that have been converted to minifloppy disk systems. 


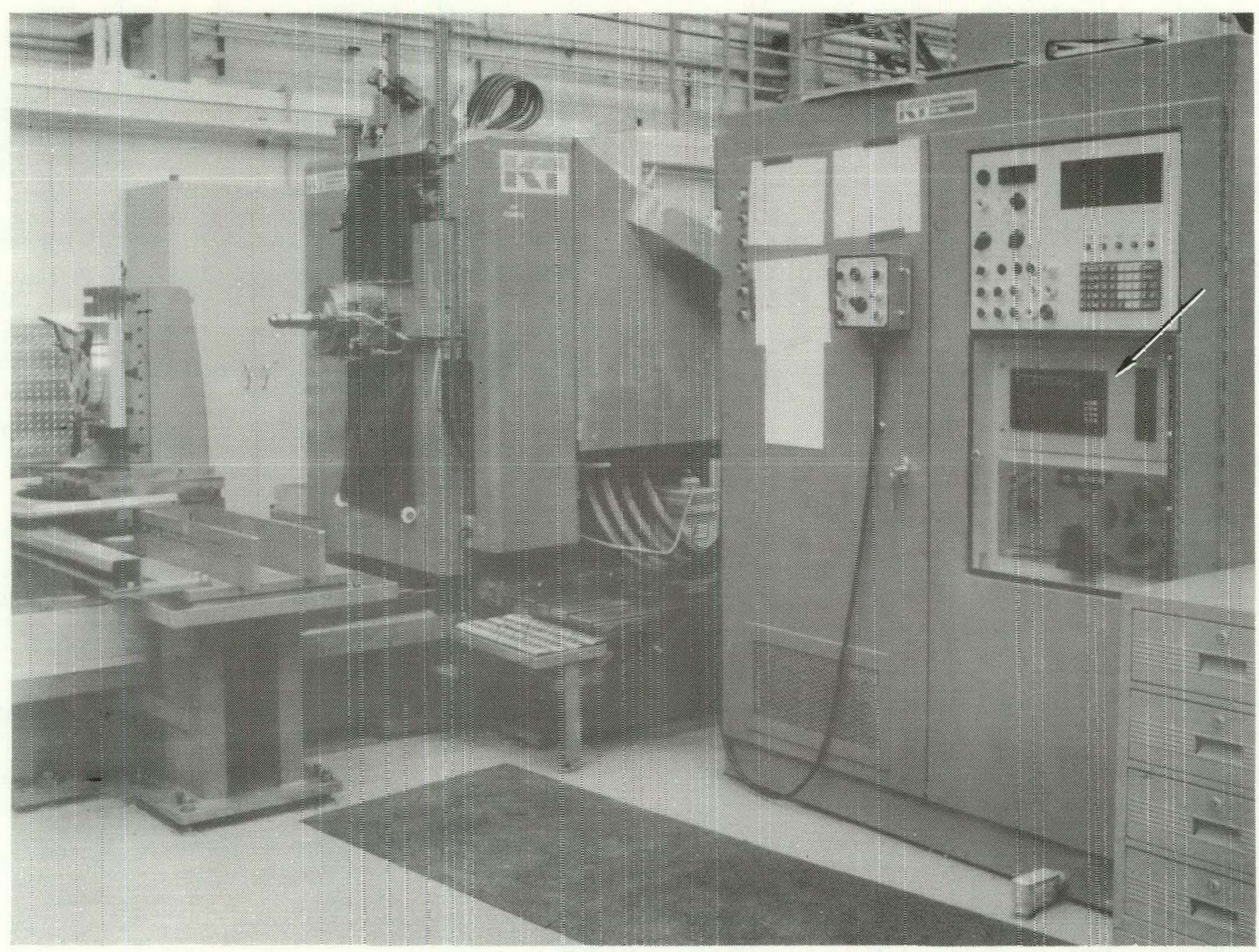

Figure A-1. Kaarry \& Trecker Model 180 Milling Machine with a $<\&$ T Modified JEC PDP-8A Computar 


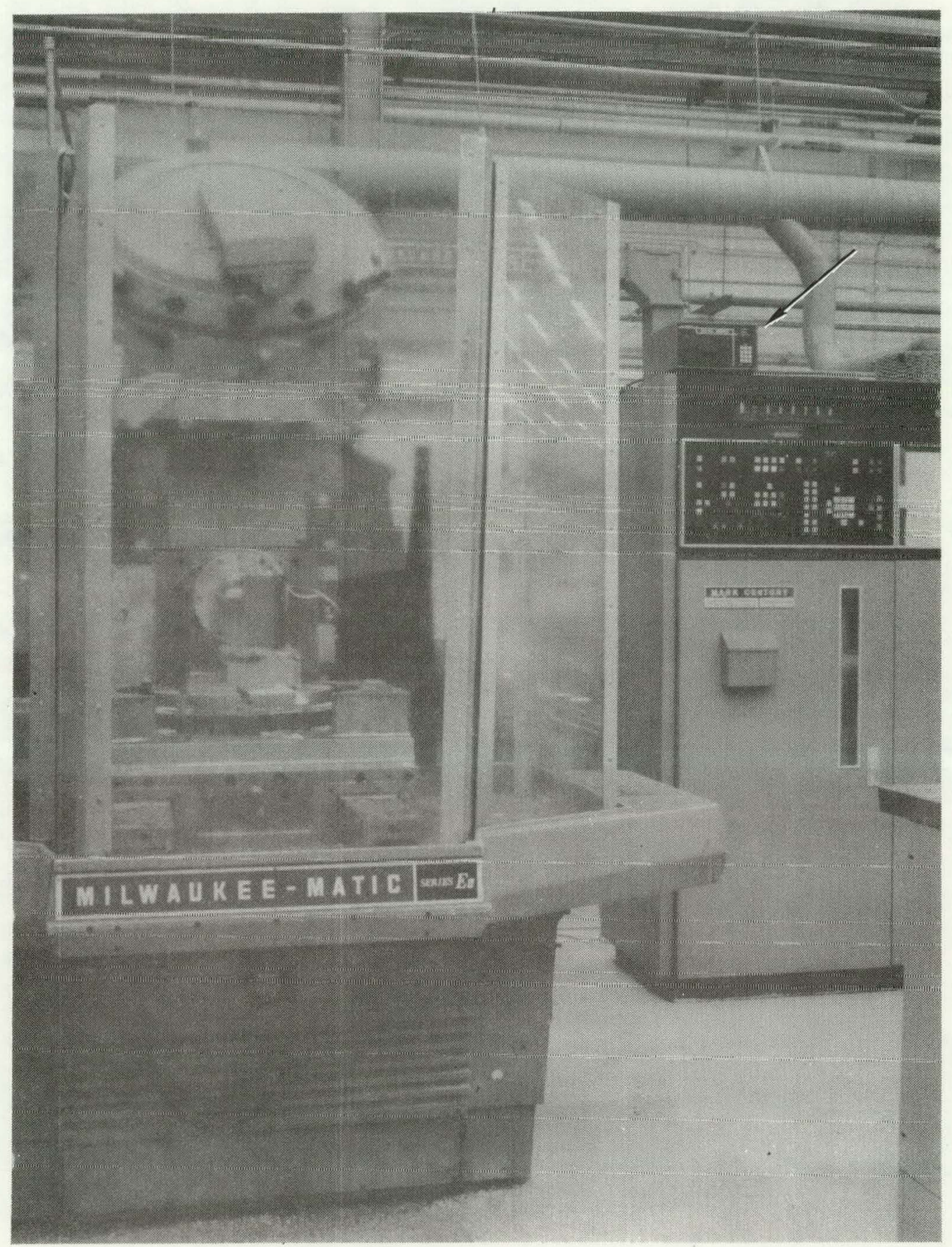

Figure A-2. Kearny \& Trecker Model Eb Milling Machine with GE Model 7500 Control 


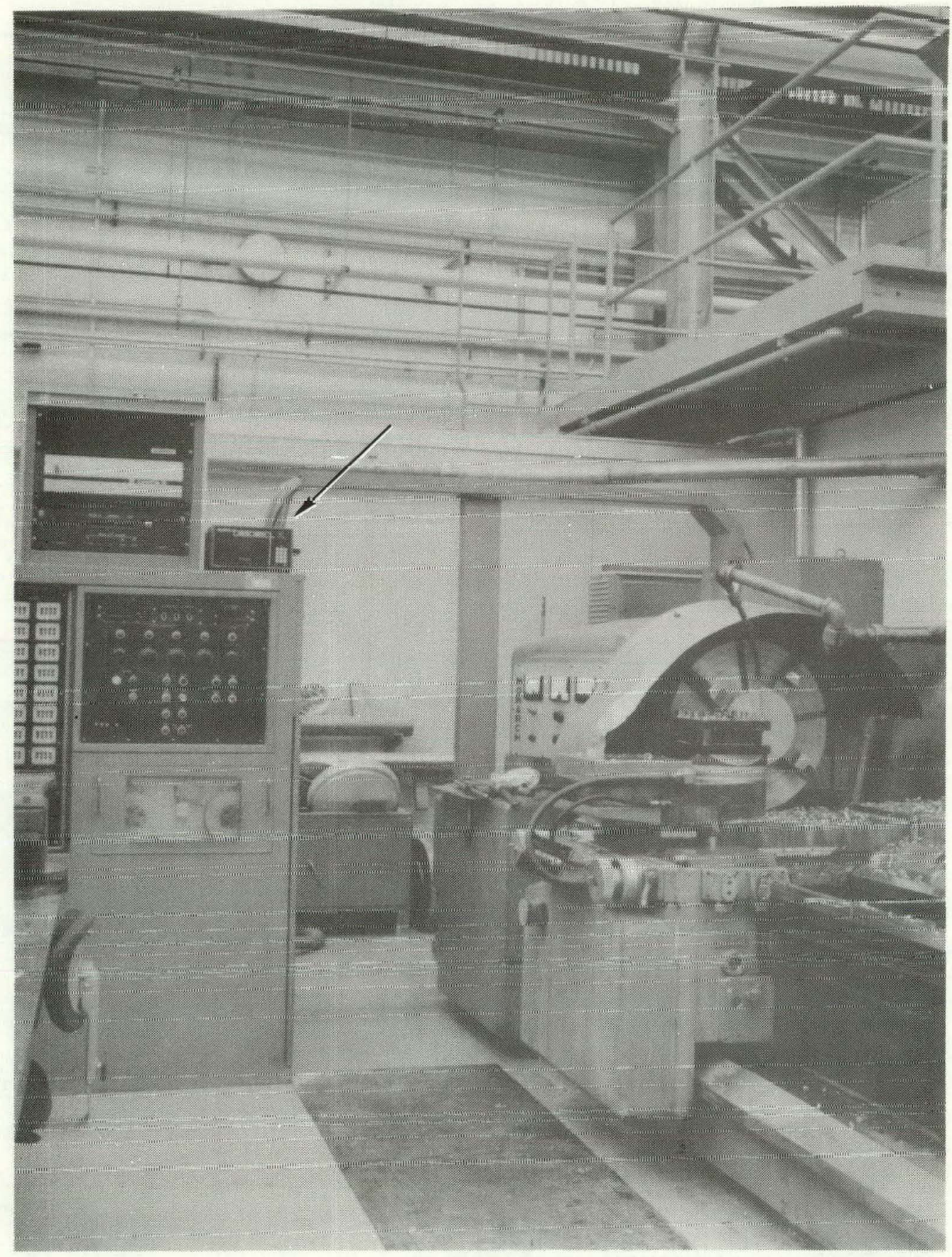

Figure A-3. Monarch Lathe with GE Model 100 Control 


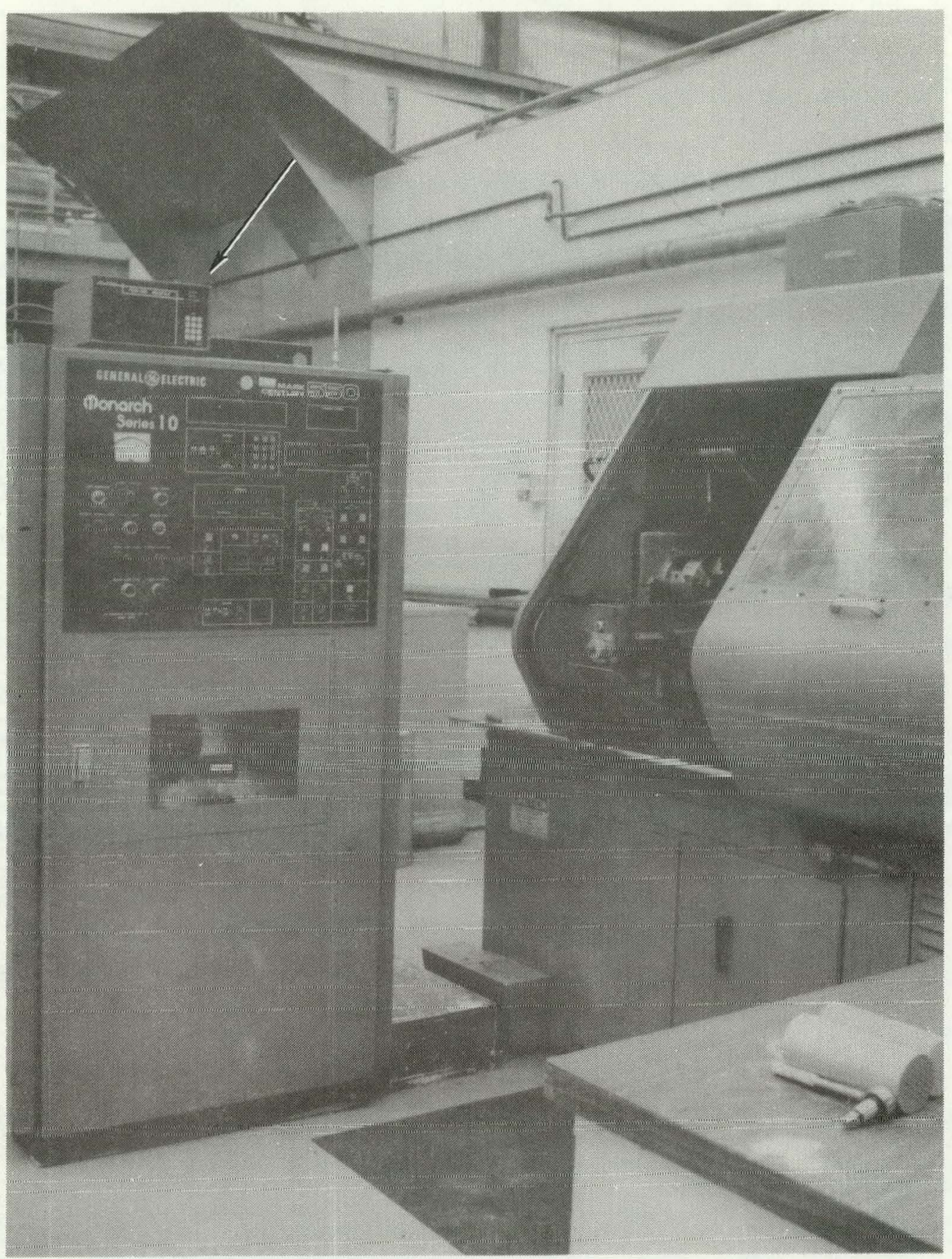

Figure A-4. Monarch Lathe Series 10 with GE 550 TX Control 


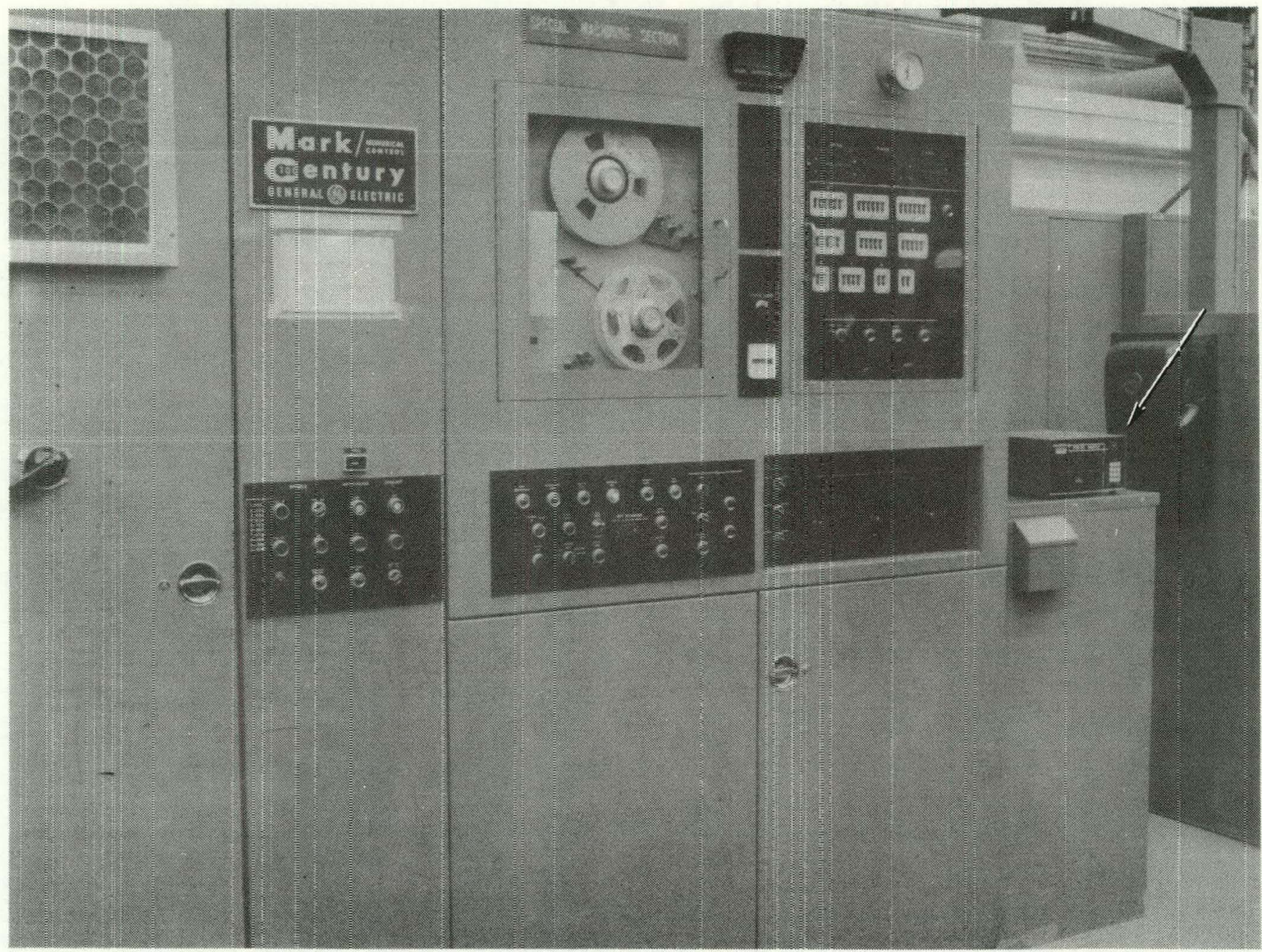

Figure A-5. Cincinnati Three-axis Milling Machine (not shown) with GE Model 100 Control 


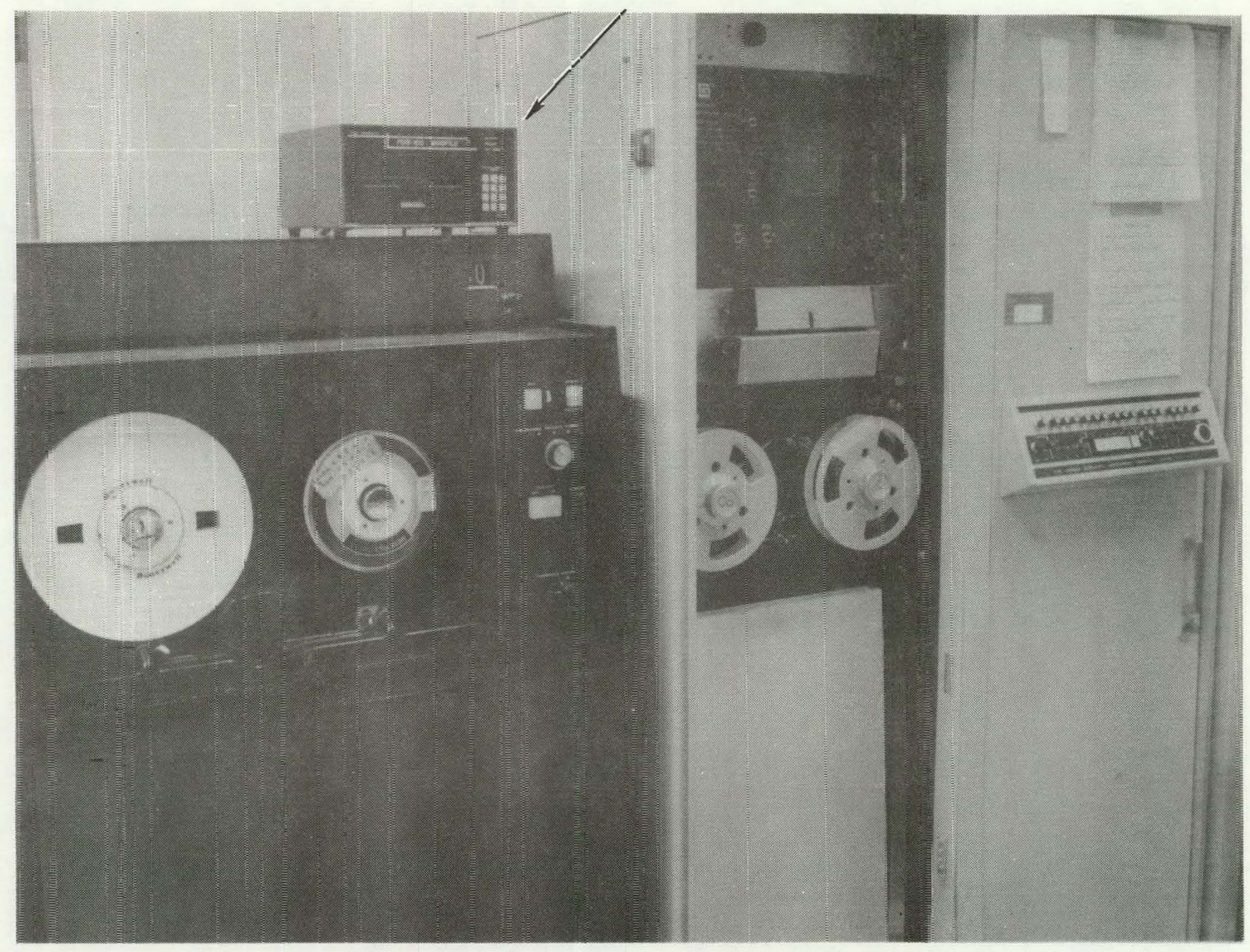

Figure A-6. Control for Gerber Photoplotter Model 2000 w'th Honeywell Computer 


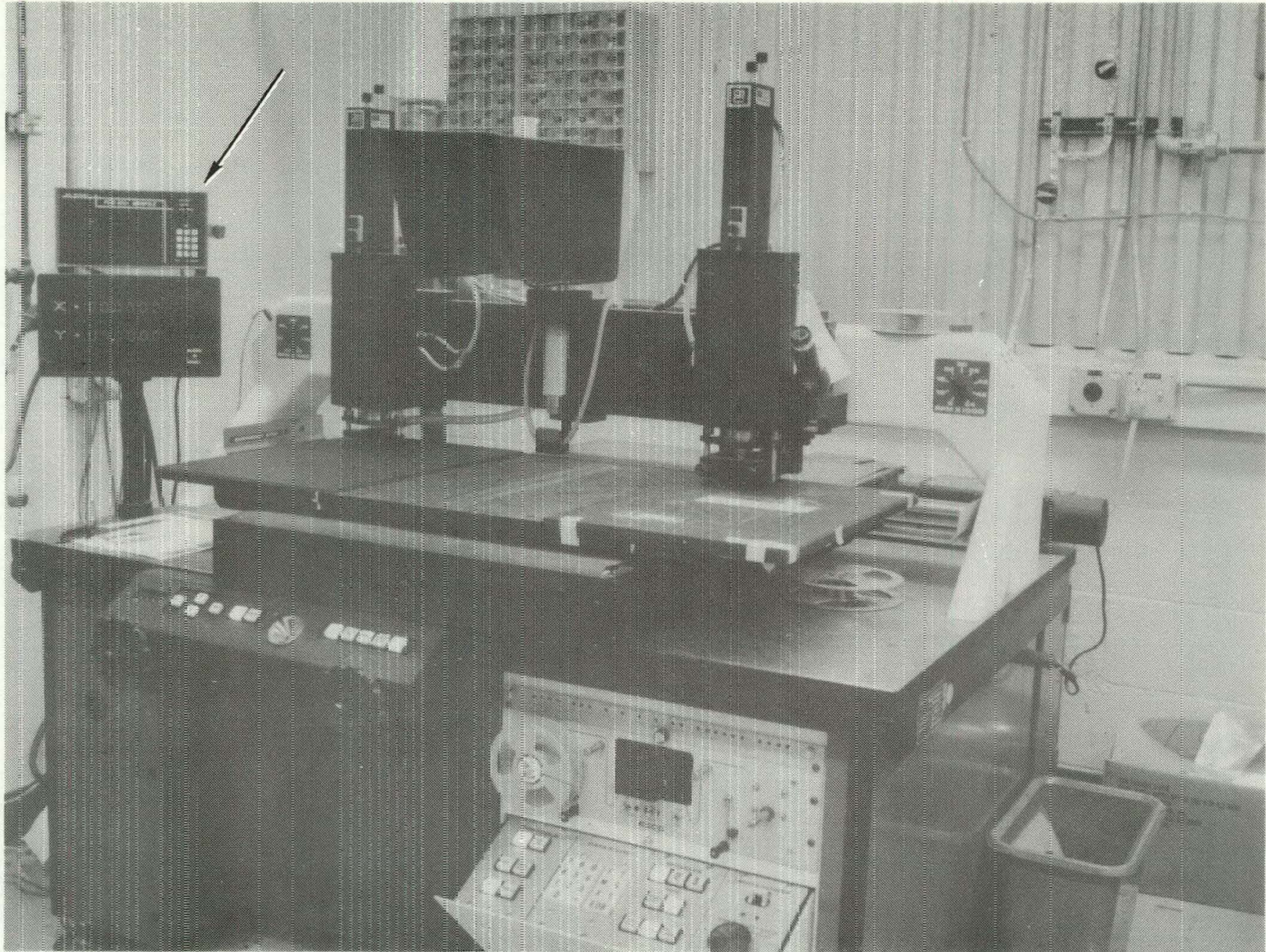

Figure A-7. DAC Drilling and Routing Machine 


\section{APPENDIX B--WIRING DIAGRAM OF DATA INPUT CIRCUITRY FOR}

EACH NC MACHINE TOOL

The following figures are wiring diagrams of the data input circuitry for each NC machine tool. 


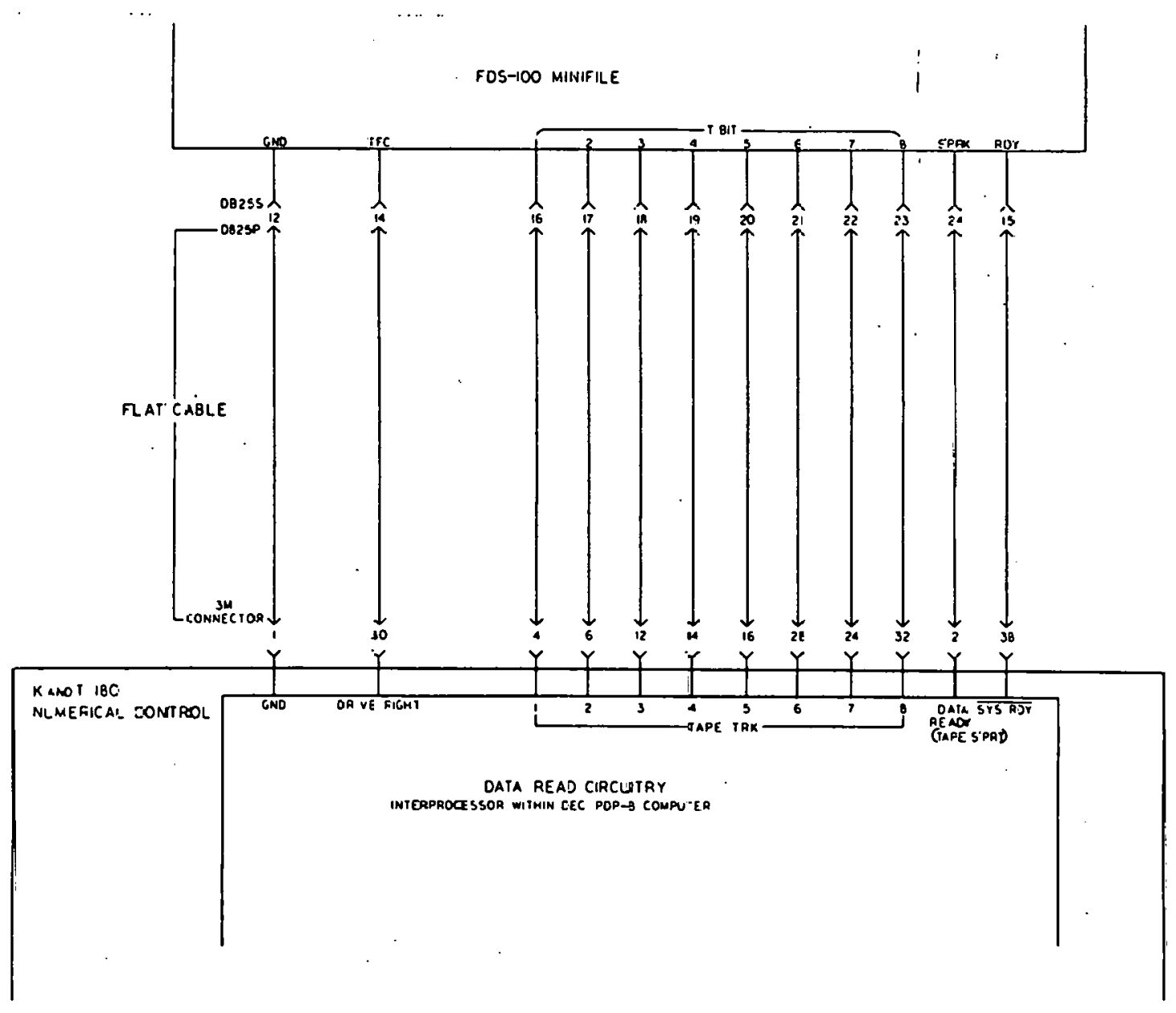

Figure E-1. Wiring Diagram for Data Input to $K$ and $T$ Mode? 180 CNC Milling Machine 

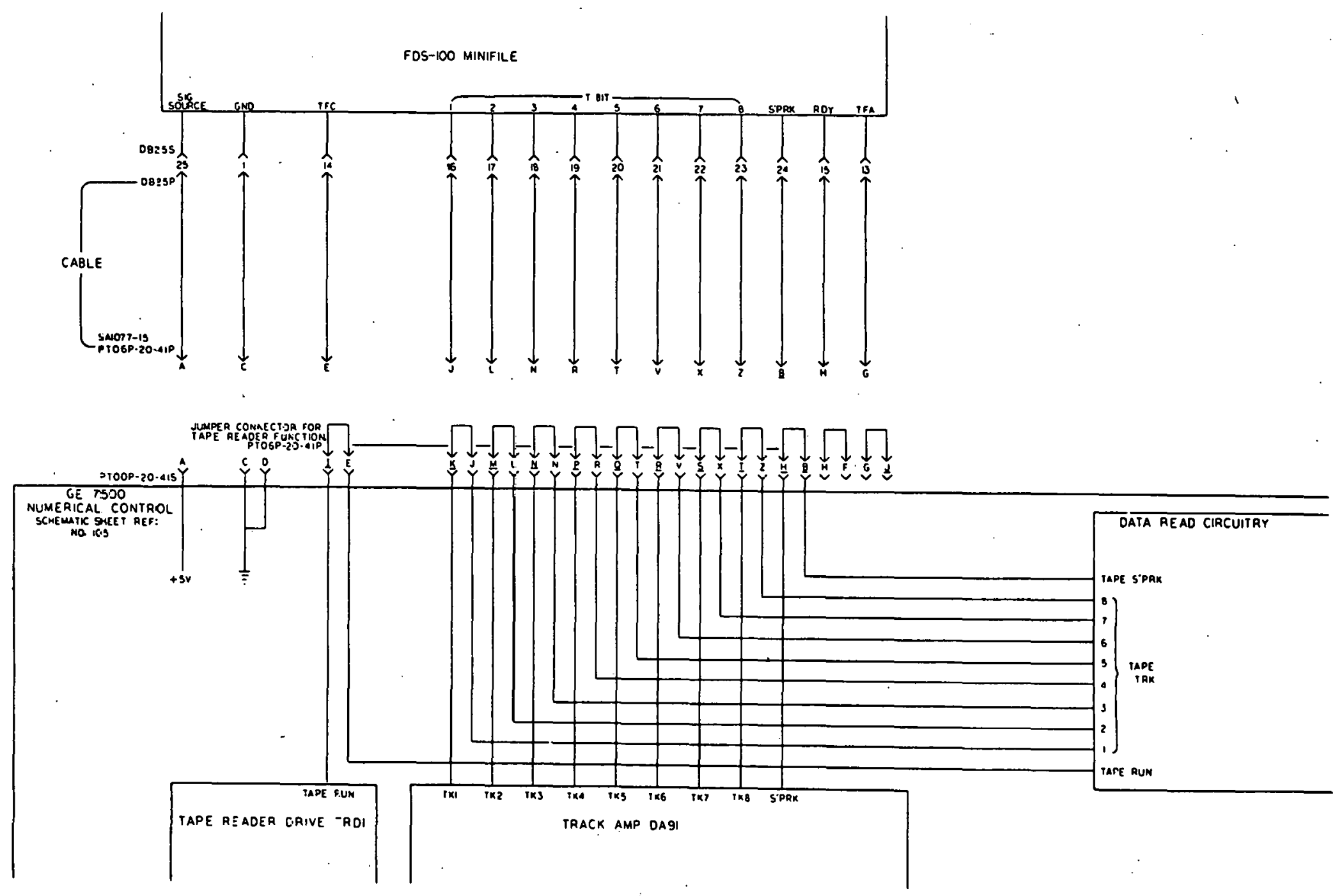

Figure B-2. Wiring Diagram for Data Input to $K$ and $T$ Model EB Milling Machine 

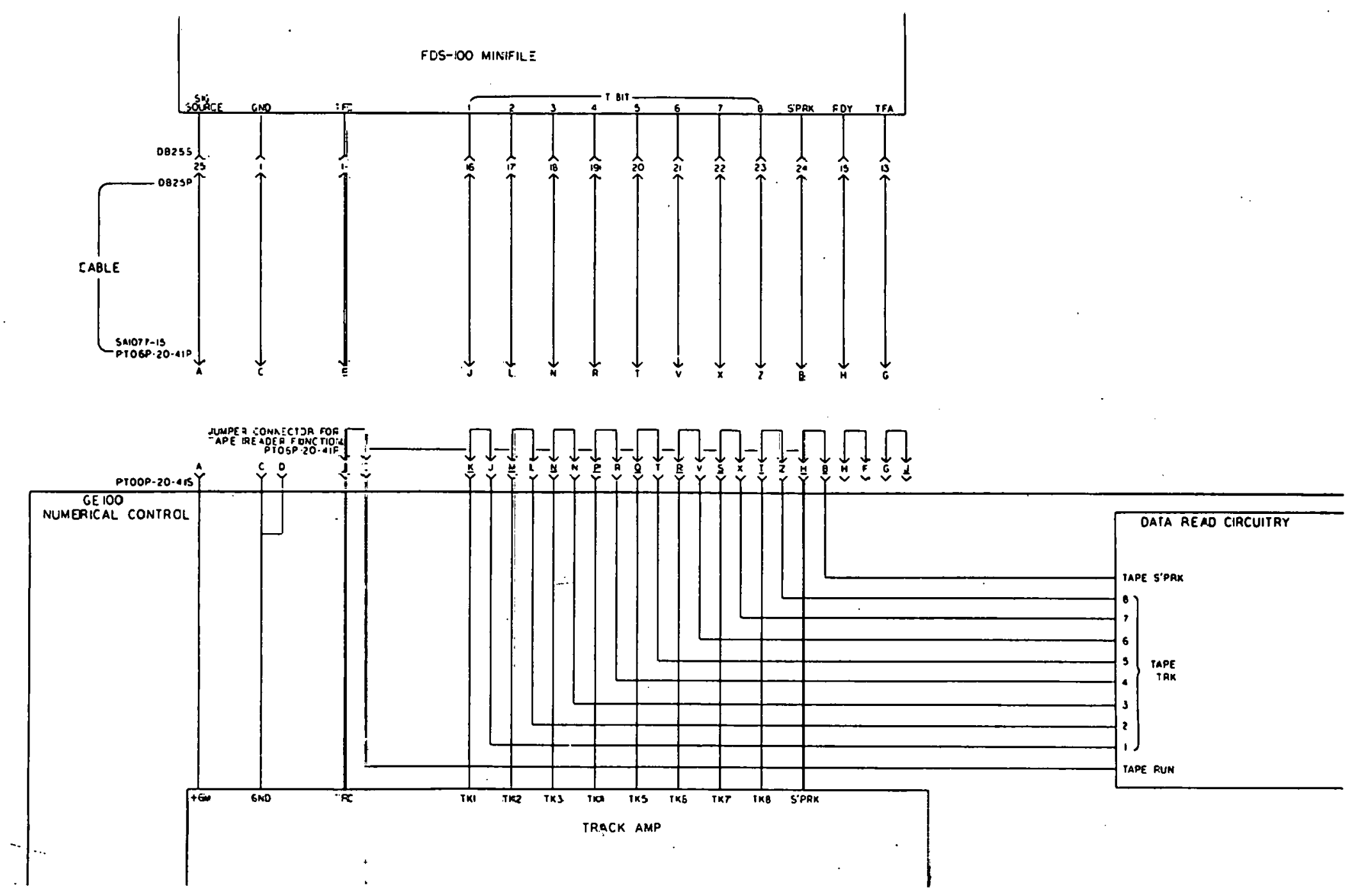

Figlire B-3. Hiring Diagram for Data Input to GE Model 100 Monarch: Lathe 


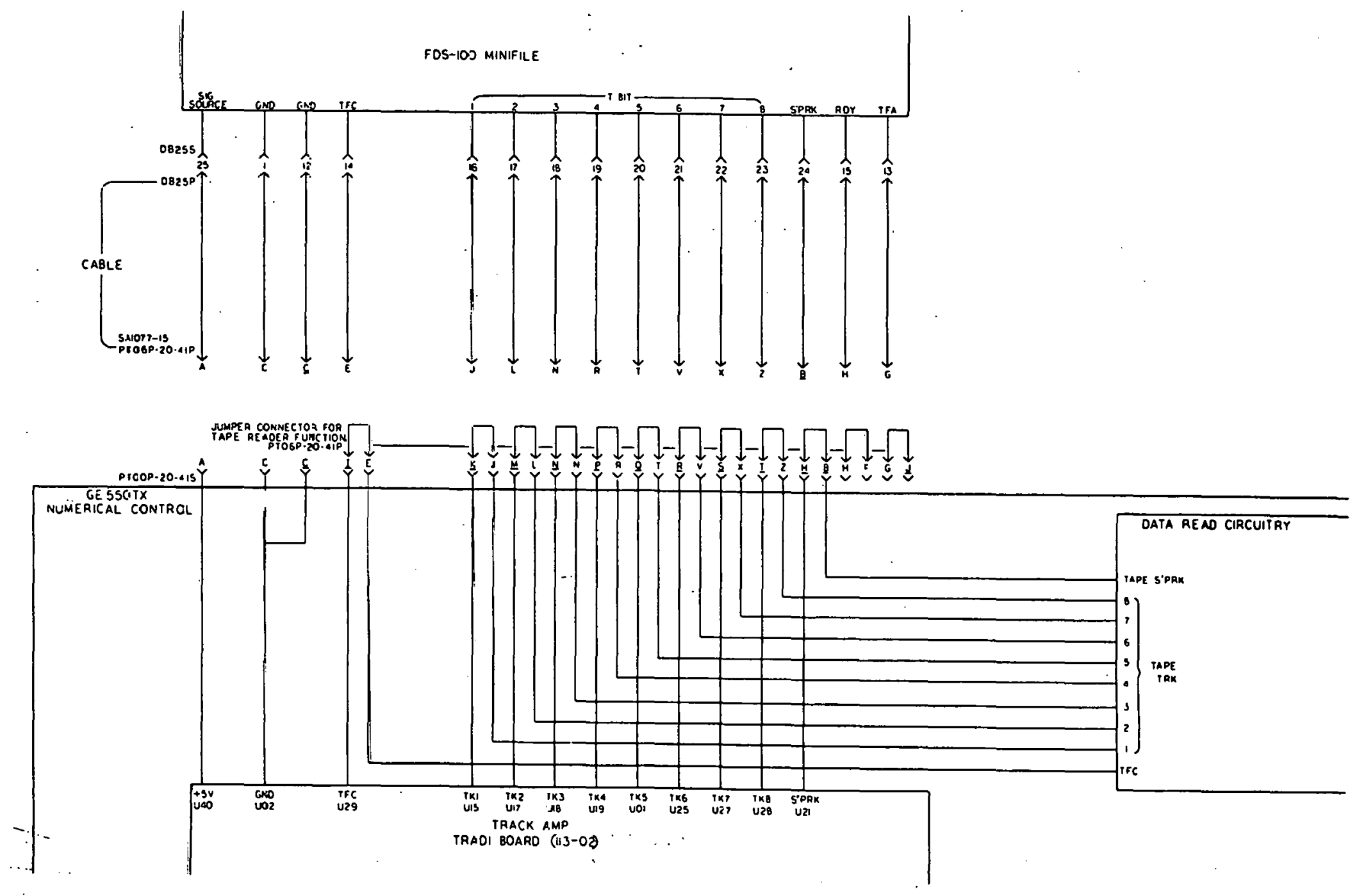
TX Monarch Series 10 Lathe 

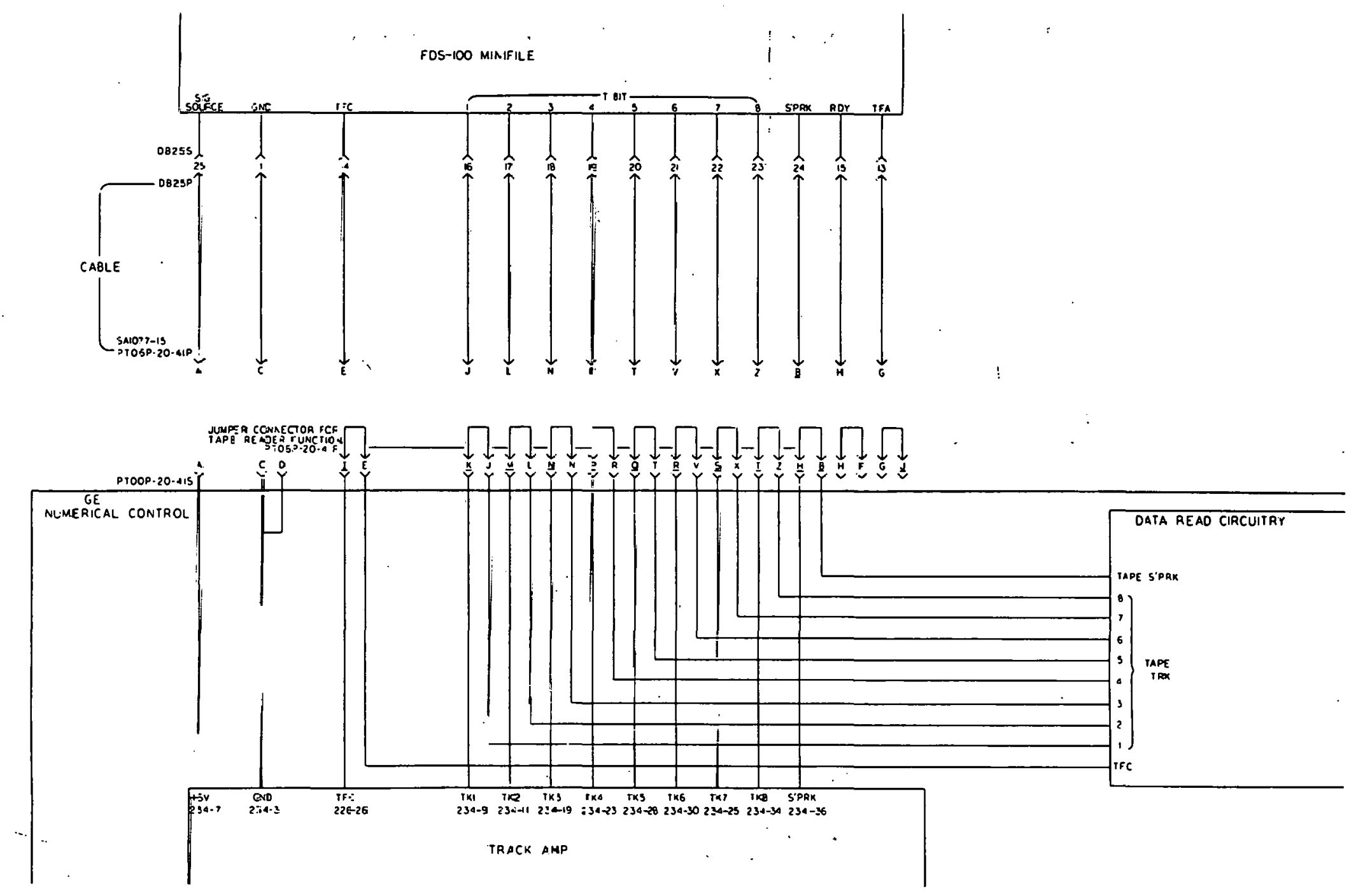

Figure B-5. W'irinc Diagram for Da:a Input to GE Model 100 Cincinnati Three-axis Milling Machine 

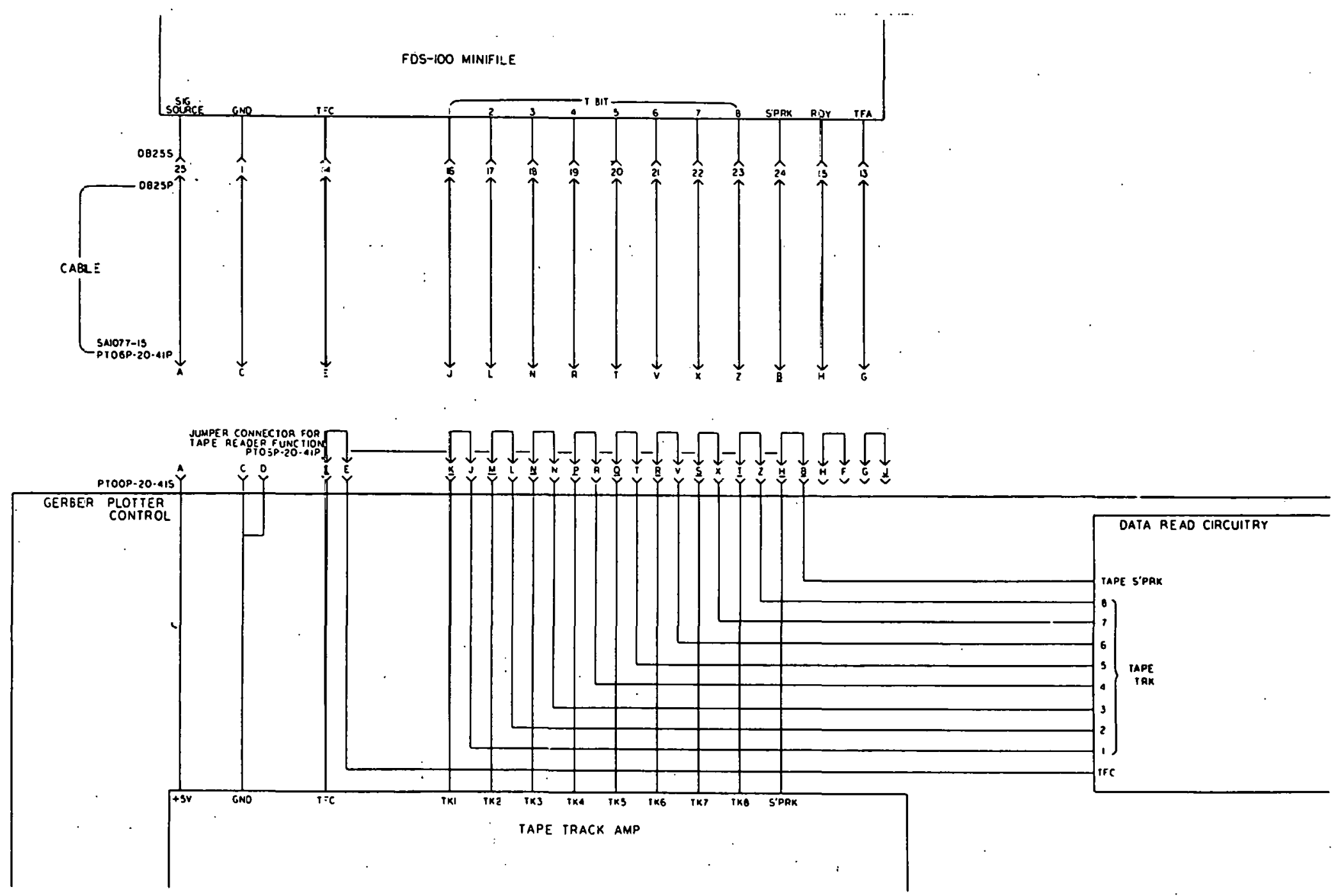

Figure B-6. Wiring Diagram for Data Input to Gerber Photoplotter 

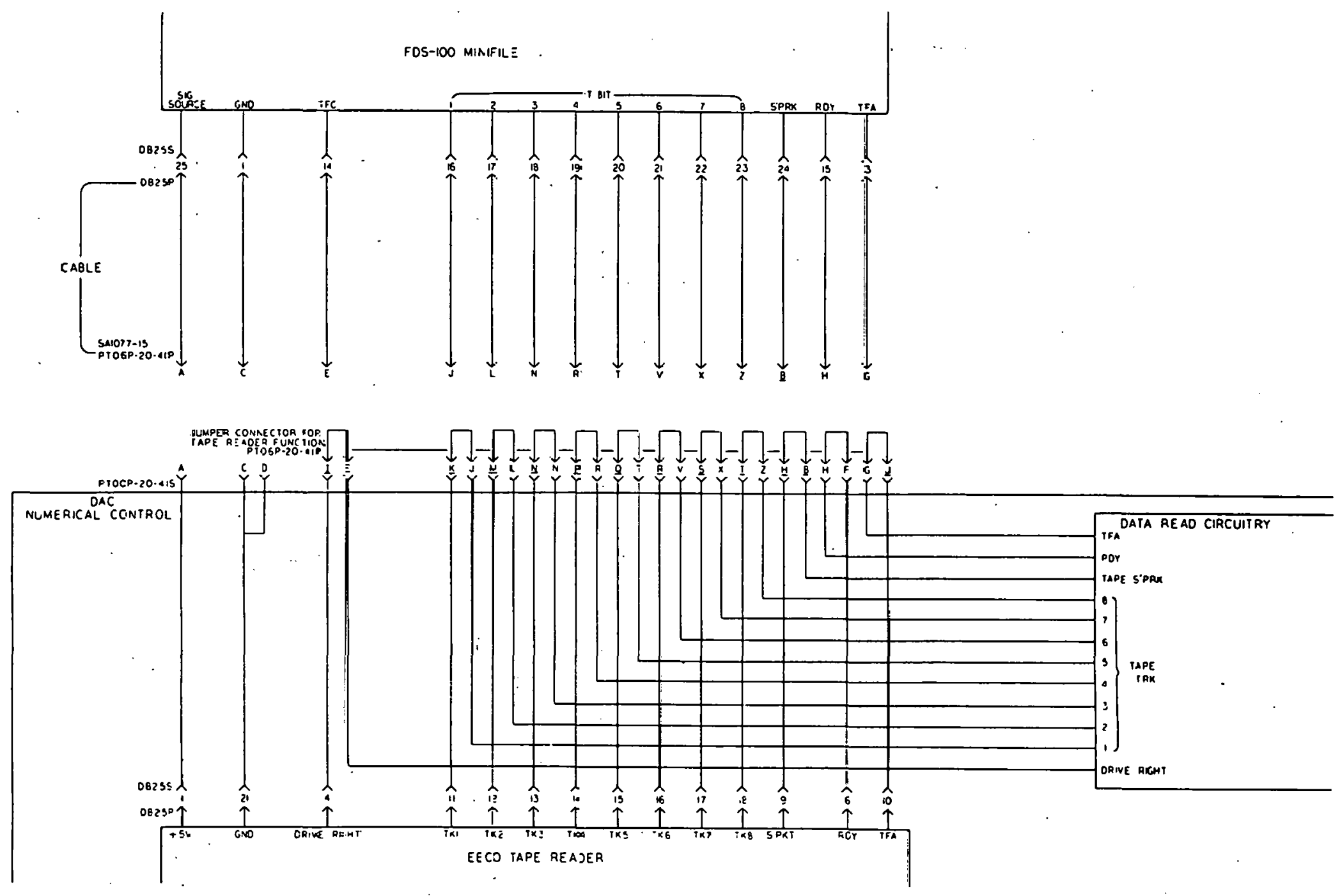

Figure B-7. Wiring Diagram for Data Input to DAC Drilling Machine 


\section{APPENDIX C--F ILE MANAGEMENT COMMANDS}

This appendix contains explanations of the file management commands, system status information, switch selectable options, and information on the tape emulator. 
File Management Commands

$1 * N \# \quad$ DEFINE FILE

This command is for creating a file and enables writing on the diskette beginning at the first available sector. The entry $N$ is a one or two-digit number (1 - 99) that is entered into the directory. Future access to the file is identified by that number. Data transmitted to the minifile are recorded in blocks of 160 bytes. The Close File command, which terminates this operation, causes any partial blocks to be recorded, and a final entry is made in the directory.

\section{$2 * N \# \quad$ SELECT F ILE}

Th is command selects for reading the file $N$ that was previously generated by a Define File command. The directory is searched for the entry $N$ and the beginning of that file is obtained. The data recorded in that file are transmitted to the host or receiving device until the end of the file is detected or a Close File command is entered.

3\#

CLOSE FILE

The Close File command is entered by the operator to mark the completion of a Define File or Select File operation. In most applications, it is only necessary when all the data for a given file are transmitted to the minifile. Select file operations automatically close the file when the end of the file is detected.

$5 \#$

DIRECTORY

The Di rectory command displays the file 10 numbers recorded in the directory beginning with the first entry. Depressing the \# key causes successive entries in the directory to be displayed.

$6 \#$

ENABLE DC2/DC4 DETECTION

This command is provided with the (-SP5) firmware option. When enabled, the minifile begins recording data following the first DC2 character and stops recording when DC4 is detected.

$7 \#$

DISABLE DC2/DC4 DETECTION

Th is command is provided with the (-SP5) firmware option and disables the DC2/DC4 detection mechanism earlier described. 
This command displays a number maintained by the minifile firmware that is an accumulation of errors detected when reading or writing on a diskette. This command is provided to enable the operator to note marginal or deteriorating diskettes before they become unusable. The error count is initialized to zero when power is applied or when the Reset command is entered.

\section{3*N\#. SET BAUD RATE}

The Set BAUD Rate command provides a convenient method of changing the BAUD rate at the RS232C interface; thus overriding the switch settings that are only accessible by removing the cover. Entering a Reset command will set the BAUD rate back to that of the switch settings.

\section{4*N\# SYNC MODE SELECT}

This command specifies a mode for synchronizing data transmitted by the minifile to the receiving device. It is useful in that in many applications the receiving device will be unable to maintain the full rate of transfer. The modes specified by parameter $\mathrm{N}$ are as follows:

0 - No synchronization. This is the default mode when power is applied or when a Reset command is entered.

1 - Character sync mode. The minifile transmits one byte for each byte received from the host device. The value sent by the host has no significance.

2 - X-ON/X-OFF. The minifile transmits data until X-OFF character is received from the host device. Data transmission is resumed when $X-O N$ character is received.

\section{3\# . RESET}

The Reset command causes the minifile to reinitialize in the same manner as if power is applied. Any data in a write file that was not closed by the Close File command is lost.

91\# FORMAT

This command is required when a diskette is placed into service for the first time. The Format command writes all blocks, initializes the directory, and verifies the diskette.

INITIALIZE DIRECTORY

The Initialize Directory command deletes all files from the diskette. 
The Verify Diskette command performs a read check on all the blocks on the diskette. Failures are reported on the front panel numeric display.

\section{7\# COMPRESS DISKETTE}

The minifile system uses a file structure in which all the blocks on a diskette are allocated sequentially. The deletion of a file creates an unavailable area on the diskette unless the deleted file happened to be the last file defined. This command repacks the files and reclaims any space on the diskette that was unavailable due to the file deletion. The execution time is dependent on the number of deleted files, their sizes, and relative positions. In most cases, this time will not exceed three minutes.

DISPLAY FREE BLOCKS

The Display Free. Blocks command displays the available space nn the diskette.

\section{System Status Information}

System status is presented in the form of a numeric code on the front panel three-digit display. This code is identified as status by the STATUS indicator and pertains to improper operating procedures or some form nf condition or malfunction detected by the minifile.

Listed below are the status codes presented by the minifile and a description for each of the codes.

002

FILE ALREADY EXISTS

003

FILE DOES NOT EXIST

004

ILLEGAL COMMAND

005 DISKETTE FULL

006 END OF F ILE
An attempt was made to define a file with a ID number that is currently defined in the directory.

The file selected for reading or deletion cannot be found in the directory.

The cominand issued is not recognized by the minifile.

The diskette does not have room for the data transmitted or the directory has no room for an additional entry.

The minifile transmitted all the data in the selected file. 
INITIALIZE ERROR

008 FILE ALREADY OPEN

009

COMMUNICATION ERROR

100

DIRECTORY READ ERROR

101 BLOCK CHECK ERROR

103

SEEK ERROR

104

DISK TIME OUT

105

WRITE PROTECT VIOLATION
Data errors were encountered during Initialize or Format operation. The minifile makes 16 attempts to recover prior to reporting this error.

An attempt was made to define or select a file with one currently defined or selected, respectively. The Close File command must be issued to a void this condition.

This error is a signal to indicate some error condition was detected during communication with the host device. The error condition can somet imes be attributed to improper BAUD rate or STOP bit selection.

The minifile was unable to read the directory without an error. This usually indicates an unformatted diskette.

A block on the diskette could not be read without error within 16 attempts.

The minifile was unable to verify the track position on the diskette before reading or writing a block of data.

This error indicates a disk I/0 operation did not complete within two seconds. It is normally as a result of initiating a command without a diskette in the drive.

The diskette in the disk drive is write protected and the minifile attempted to write on it.

Switch Selectable Options

The FDS-100 Minifile offers a variety of switch selectable options that are set in accordance with the desired mode of operation. These options pertain to BAUD rate, number of STOP bits, hardware synchronization, and selection of features provided for some custom applications. By removing the top cover from the minifile, two eight-position DIP switches are exposed 
(D1 and D2). These switches are mounted on the serial interface card inserted at the top of the unit. The switch closest to the circuit card edge is 02 .

Two switches allow a selection of features desirable in some applications. They are somewhat related and described below.

SWITCH D2-7: when this switch is open the minifile will not send data until requested by a false to true transition of the Data Terminal Ready signal at the RS232C interface (Table A-1). This option allows the host device to strobe the data from the minifile. Switch D2-8 must be closed when this option is selected.

SWITCH 02-8: when this switch is closed, the minifile ignores the state of the input signals Data Terminal Ready and Request to Send at the RS232C. interface. When this switch is open, switch D2-7 must be closed and Data Terminal Ready and Request to Send must be true for the minifile to accept data from the host device.

Tape Emulator

This section is devoted to the FDS-100 Paper Tape Emulator, herein referred to as the tape emulator. The user should review this section carefully before attempting to interface the tape emulator with other equipment.

The tape emulator is an offspring of the FDS-100 Minifile used to record and retrieve data via an RS232C serial interface. Data are maintained by a file management technique common to the minifile and the tape emulator. The operator gains entry to the file mangement system via a front panel keyboard. Command 3 available tu lite tape enulator are a subset of those in the minifile. Primarily, only those commands that pertain to read functions are recognized.

The thterface is eight-bit parallel data and provides the signals necessary to emulate paper tape readers. A number of switch and strap selectable options on the interface card are provided to alter the signals levels, polarity, and timing.

\section{Dperation}

The tape emulator is operated in the same manner as the minifile. Commands are entered by the operator via the front panel keyboard. Operational status is provided by a three-digit numeric display. The following are the commands and numerical status codes offered by the tape emulator. 
TABLE A-1

RS232C INTERFACE CONNECTOR (DB25S) PIN ASSIGNMENTS

\begin{tabular}{|l|l|l|l|}
\hline PIN & SIGNAL & DIRECTION & COMMENT \\
\hline 1 & PROTECTIVE GROUND & & DC COMMON \\
2 & TRANSMIT DATA & INPUT & \\
3 & RECEIVE DATA & OUTPUT & MUST BE TRUE * \\
4 & REQUEST TO SEND & INPUT & TRUE WHEN FILE OPEN \\
5 & CLEAR TO SEND & OUTPUT & TRUE WHEN FILE OPEN \\
6 & DATA SET READY & OUTPUT & DC COMMON \\
7 & SIGNAL GROUND & ALWAYS TRUE \\
8 & DATA CARRIER DETECT & OUTPUT & MUST BE TRUE * \\
20 & DATA TERMINAL READY & INPUT & \\
\hline
\end{tabular}

* stgNal is IGNORED WHEN SWITCh POSITION D2-8 IS CLOSED 


\begin{tabular}{|c|c|}
\hline Entry Sequence & Command \\
\hline $2 * N \#$ & SELECT FILE \\
\hline $3 \#$ & CLOSE F ILE \\
\hline $4 \#$ & DISPLAY FREE BLOCKS \\
\hline $5 \#$ & DIRECTORY \\
\hline $12 \#$ & DISPLAY ERROR COUNT \\
\hline $73 \#$ & RESET \\
\hline $96 \#$ & VERIFY DISKETTE \\
\hline Status Code & Meaning \\
\hline 003 & FILE DOES NOT EXIST \\
\hline 004 & ILLEGAL COMMAND \\
\hline 006 & END OF FILE \\
\hline 008 & FILE ALREADY OPEN \\
\hline 009 & COMMUNICATION ERROR \\
\hline 100 & DIRECTORY READ ERROR \\
\hline 101 & BLOCK CHECK ERROR \\
\hline 103 & SEEK ERROR \\
\hline 104 & DISK TIME OUT \\
\hline
\end{tabular}

\section{Parallel Interface}

The parallel interface is eight-bit parallel data with handshaking siynals to synchronize communication with the host machine. Input and output signals are programmable for signal voltage level, active stage, and timing. Table A-2 shows the programmable features at the interface card. For the purpose of simplifying the interface description, the active status are assumed 0 volts. Timing relationships are proportional to the character rate which is an adjustable feature on the interface card.

Table A-3 shows the connector assignments for each of the input and output signals. The following is a description for each of the signals shown at the interface connector. 
TABLE A-2

PROGRAMMABLE FEATURES AT THE INTERFACE CARD

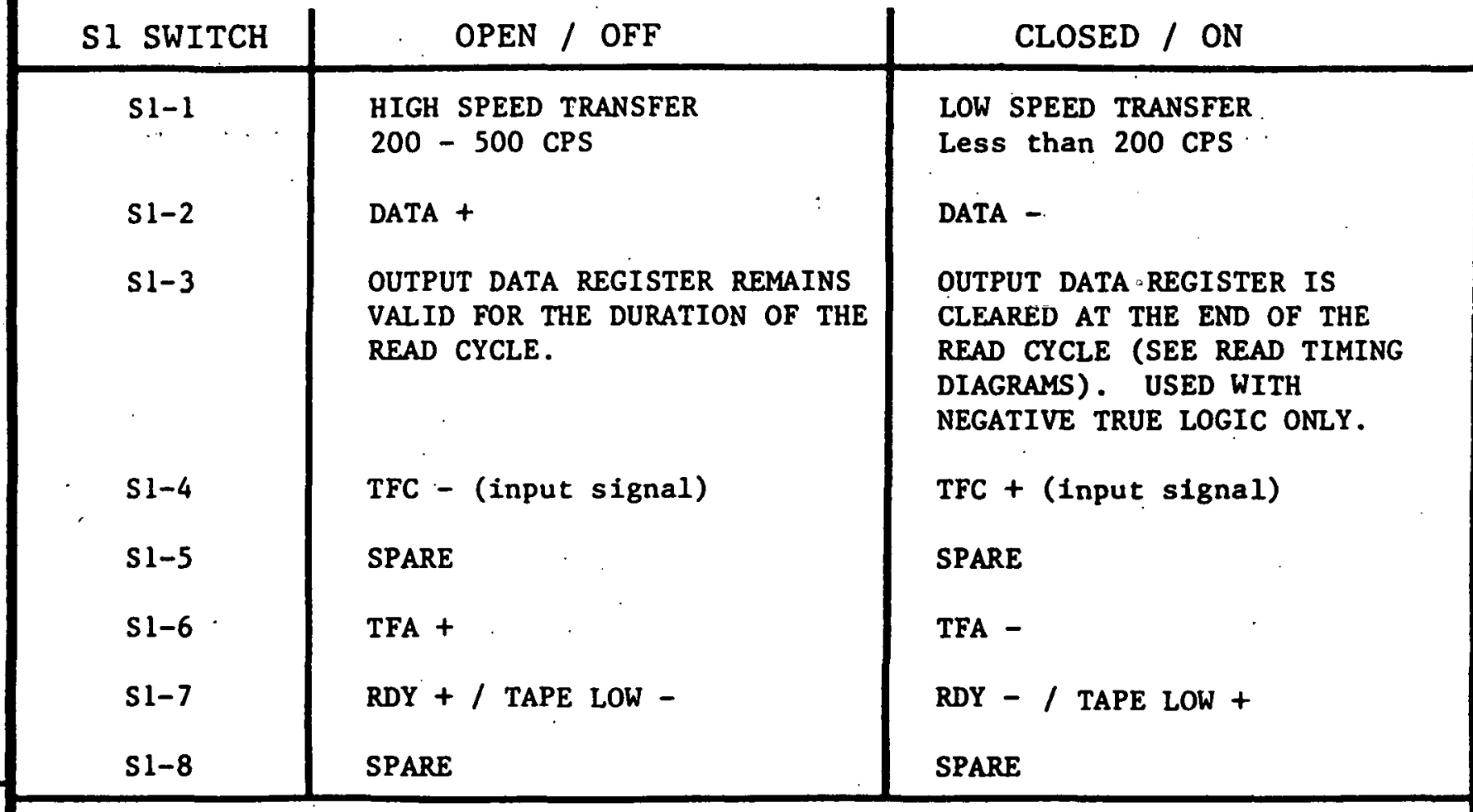

\begin{tabular}{|l|l|}
\hline JUMPER & \\
SELECTION & DESCRIPTION \\
\hline E1 - E2 & SPRK - \\
E1 - E3 & SPRK + \\
E4 - E5 & TFC LEVEL TRIGGER (SLEW MODE) \\
E4 - E6 & TFC EDGE :TRIGGER (STEP MODE / SINGLE CHARACTER \\
E9 - E8 & TAPE LOW ON PIN 15 OF I/O CONNECTOR \\
E7 - E9 & READY ON PIN 15 OF I/O CONNECTOR \\
E10- E11 & SIGNAL LEVELS 0 - 12V \\
E10- E12 & SIGNAL LEVELS DERIVED FROM SIGNAL SOURCE VOLTAGE \\
E10- E13 & SIGNAL LEVELS O - 5V \\
&
\end{tabular}


TABLE A-3

READER INTERFACE I/O CONNECTOR

\begin{tabular}{|c|c|c|}
\hline PIN & SIGNAL & MNEMONIC \\
\hline $\begin{array}{r}1 \\
14 \\
2 \\
15 \\
3 \\
16 \\
4 \\
17 \\
5 \\
18 \\
6 \\
19 \\
7 \\
20 \\
8 \\
21 \\
9 \\
22 \\
10 \\
23 \\
11 \\
24 \\
12 \\
25 \\
13\end{array}$ & $\begin{array}{l}\text { GND } \\
\text { TAPE FORWARD COMMAND } \\
\text { GND } \\
\text { TAPE LOW / READY } \\
\text { GND } \\
\text { CHLANEL } 1 \\
\text { GND } \\
\text { CHANNEL } 2 \\
\text { GND } \\
\text { CHANNEL } 3 \\
\text { GND } \\
\text { CHANNEL } 4 \\
\text { GND } \\
\text { CHANNEL } 5 \\
\text { GND } \\
\text { CHANNEL } 6 \\
\text { GND } \\
\text { CHANNEL } 7 \\
\text { GND } \\
\text { CHANNEL } 8 \\
\text { GND } \\
\text { SPROCKE'I CLOCK } \\
\text { GND } \\
\text { SIGNAL SOURCE VOLTAGE } \\
\text { TAPE FORWARD ACKN }\end{array}$ & $\begin{array}{l}\text { TFC } \\
\text { RDY } \\
\text { TBIT } 1 \\
\text { TBIT } 2 \\
\text { TBIT } 3 \\
\text { TBTT } 4 \\
\text { TBIT } 5 \\
\text { TBIT } 6 \\
\text { TBIT } 7 \\
\text { TBIT } 8 \\
\text { SPRK } \\
+5 V D \quad-+12 V D C \\
\text { TFA }\end{array}$ \\
\hline
\end{tabular}


TFC

TFA

RDY

TBIT $1-8$

SPRK

$+5 V D C$ to

$+12 \mathrm{VDC}$
TAPE FORWARD COMMAND. The tape forward command is generated by the host machine and causes the tape emulator to advance characters (i.e., step forward). The TFC input is strap selectable on the parallel interface card for either step mode or slew mode operation. In the step mode of operation, the tape emulator advances on character for each leading edge transistion of the TFC signal. In the slew mode of operation, the tape emulator advances one or more characters depending on the duration TFC is held active.

TAPE FORWARD ACKNOWLEDGE. Tape forward acknowledge is transmitted in response to TFC. It is not always required to use this signal for proper operation of the interface. It is provided for some controllers or host devices that utilize this. signal to cause a release of TFC.

READY/TAPE LOW. This signal is strap selectable to one of two meanings. If strapped as a READY signal, it provides to the host device the indication the tape emulator is in a read or step forward cycle. It is not required to utilize this signal providing the timing requirements are met. If strapped as a tape. low indicator, this signal will remain active until a file is selected by the operator.

TRANSMIT BITS/CHANNELS 1-8. These outputs are the eight data bits as would be provided by a paper tape reader. One switch selectable option is available with 0-volt TRUE convention. With the S1-3 switch position closed, the outputs are forced to logic zero at the end of a given step forward cycle, thus simulating the GAP between characters on paper tape.

SPROCKET CLOCK. The sprocket clock is provided for the host machine to strobe the eight bits of data to its internal register. The leading and trailing edge of SPRK are valid.

SIGNAL SOURCE VOLTAGE. This input allows the signal levels to be defined at the interface. This is especially valuable when. the logic levels needed are something other than $0-5$ or $0-12$ volts. 


$$
\text { Do NoT film }
$$

UNL IMI TED RELEASE

INITIAL DISTRIBUTION

Bendix Corporation

Kansas City Division

P. 0. Box 1159

Kansas City, MO 64141

Att n: D. Bartel

Monsanto Research Corporation

Mound Facility

P. 0. Box 32

Mi ami sburg, $\mathrm{OH} 45342$

Att n: G. Mahfouz

Rockwell Internationa 1

Kocky $\mathrm{Fl}$ ats $\mathrm{Pl}$ ant

P. 0. Box 464

Colden, CO 80401

Att n: P. E. Beaudet

R. D. Dixon

D. Hnath

R. R. Burleson, LLNL, L-330

J. L. Chrislock, LLNL, L-3̇30

J. Gonsalves, 1481

P. Plomp, 1483

R. S. Claassen, 8000 ; Attn: D. M. 01 son, 8100

A. N. BLackwel 1, 8200

B. F. Murphey, 8300

D. L. llart ley, 8500

J. F. Jones; 8274 ; $\Lambda t t n:$ P. K. Neighbors, 8274

L. Gutierrez, 8400

V. Bl ack, 8414

J. G. Pergrossi, 8414-2; Attn: B. Affeldt, 8414-2

L. N. Tallerico, 8415

J. F. Barham, 8460

D. N. Bray, 8466

J. E. Hopwood, 8466 (8)

Publications Uivision, 8265 , TIC (27)

Publications Division, 8265/Technical Library Processes Division, 3141

Technical Library Processes Division, 3141 (3)

M. A. Pounds, 8214, for Central Technical Files (3) 


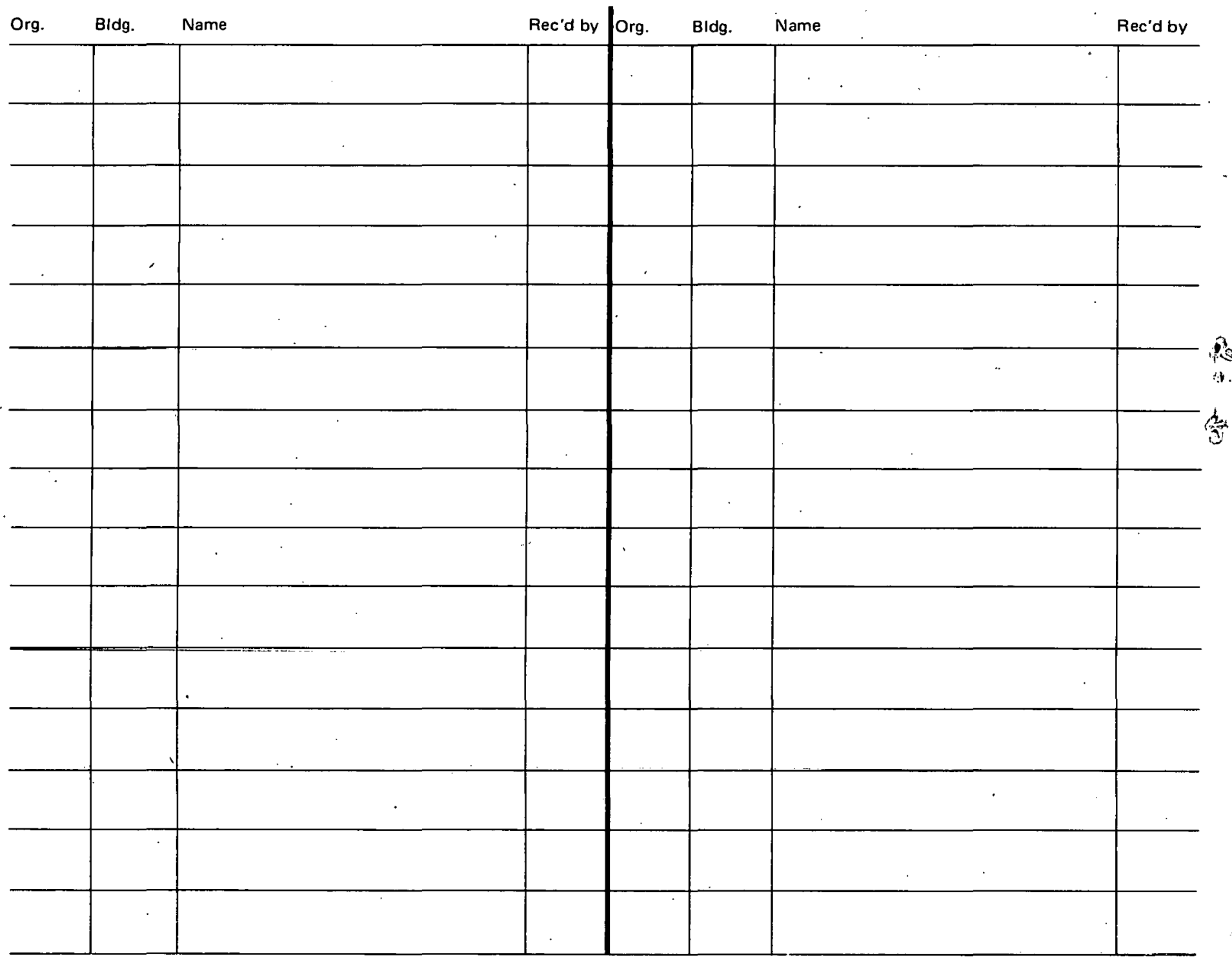

T.2

it.

in. 